\title{
Condicionantes de Clubes de Convergência no Brasil
}

\author{
- JoÃo luis Brasil Gondim* - Flávio Ataliba Barreto** \\ - JosÉ RAIMUNDO CARVALHO ***
}

\begin{abstract}
RESUMO
Os principais estudos sobre convergência, no Brasil, têm se concentrado na análise da $\beta$-convergência. Neste artigo é reexaminada essa questão utilizando a metodologia de Quah (1997) para analisar a evolução da distribuição da renda condicionada dos estados e municípios entre 1970 e 2000 . São efetuados três tipos de estimações: a) densidades estimadas pelo método de suavização por núcleo; b) estimação de núcleos estocásticos para analisar os movimentos das economias ao longo do espaço de rendas para identificar a formação de clubes de convergência e; c) estimação de núcleos estocásticos condicionados à localização geográfica, escolaridade, abertura comercial e desigualdade de renda, com o objetivo de identificar possíveis responsáveis pelo padrão de convergência encontrado. $O$ uso das metodologias acima permitiu identificar a tendência à formação de clubes de convergência no Brasil, como já identificados por Mossi et alii (2003) e Andrade et alii (2004). As variáveis de localização geográfica e nível inicial de escolaridade surgem como os principais condicionantes desse processo.
\end{abstract}

\section{PalavRAS-CHAVE}

núcleo estocástico, clubes de convergência, Estados e municípios brasileiros

\begin{abstract}
The main studies about convergence in Brazil have concentrated in the $\beta$-convergence analysis. The present article reexamines this issue using a methodology developed by Quah (1997) to analyze the evolution over time of the conditioned distribution of income among Brazilian states and municipalities between 1970 and 2000. Three kinds of estimation are done: a) kernel smoothed densities methods; $b$ ) estimation of stochastic kernels to analyze the movements of the economies over the income space with the aim to identify convergence clubs in specific space intervals; c) estimation of stochastic kernels conditional on geographic localization, education, openness to international trade and income inequality, with the objective to identify possible explanations to the observed pattern of convergence. The use of the methodologies above allowed us to identify a tendency of club formation in Brazil, as already identified by Mossi et all (2003) and Andrade et all (2004). Variables concerning geographical localization and level of education appeared as the main conditioner for this process.
\end{abstract}

\section{KEY WORDS}

stochastic kernel, convergence clubs, Brazilian states and municipalities

\section{JEL ClASSIFICATION}

O54, $\mathrm{Cl} 4$

\footnotetext{
* Mestre em Economia pelo CAEN/UFC, Auditor-Fiscal da Receita Federal. E-mail: jlgondim@terra.com.br.

** Pós-Doutor em Economia, Universidade Harvard/EUA, Professor do Curso de Pós-Graduação em Economia CAEN/UFC. E-mail: ataliba@ufc.br.

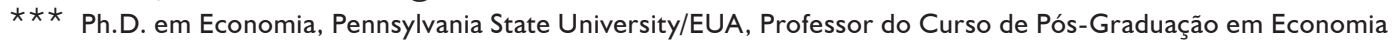
CAEN/UFC. E-mail: josecarv@ufc.br.

Endereço para contato: Curso de Pós-Graduação em Economia-CAEN/UFC - Avenida da Universidade 2700, $2^{\circ}$ andar, Benfica, 60.020-180 - Fortaleza, Ceará.

(Recebido em novembro de 2004. Aceito para publicação em março de 2006).
} 


\section{INTRODUÇÃO}

Os estudos empíricos sobre convergência, no Brasil, têm se concentrado principalmente em testar a hipótese de $\beta$-convergência (absoluta e condicional), também conhecidas como regressões Barro-Baumol, referências a Barro (1991) e Baumol (1986). ${ }^{1}$ A maioria dos trabalhos sugere a inexistência de convergência ou um processo muito lento de aproximação da renda per capita entre os Estados brasileiros. (Ferreira e Diniz, 1995; Ellery e Ferreira, 1996; Ferreira, 1996, 1999, 2000; e Zini Jr., 1998).

Por outro lado, pouca preocupação tem sido dada à investigação dessa questão utilizando amostras territoriais mais desagregadas, seja para municípios, microrregiões ou mesorregiôes. A dificuldade, até bem pouco tempo, na obtenção de dados confiáveis a esses níveis tem sido uma das causas principais para o reduzido número de estudos nessa área. Azzoni e Menezes (2000), no entanto, utilizando dados em painel, encontram evidências para a convergência condicional entre as regiốes metropolitanas do Brasil, no período de 1981 a 1996.

A inexistência de um padrão claro de convergência entre as unidades federativas no Brasil, nas últimas décadas, reforça as discussões sobre o papel aparentemente ineficaz das políticas de redução das desigualdades regionais colocadas em prática. Por outro lado, a ausência de convergência verificada pode também ser explicada por problemas metodológicos advindos em se estimar um valor para $\beta$, numa equação de convergência, utilizando dados históricos cross-section para modelos de crescimento com a estrutura teórica de Solow ou mesmo na formulação de Ramsey para economias fechadas.

As principais críticas referentes às regressóes do tipo Barro-Baumol foram apontadas inicialmente por Friedman (1992) e Quah (1993). Esses autores consideram que esse tipo de regressão em direção à média pode apresentar a Falácia de Galton. ${ }^{2} \mathrm{O}$ ponto principal da crítica é que como o coeficiente estimado representa um valor médio da amostra utilizada, esse experimento pode na verdade não estar representando de forma clara sua real tendência.

1 Para melhor entendimento do significado de $\beta$-convergência veja Barro e Sala-i-Martin (1992) e Quah (1996).

2 A Falácia de Galton tem um significado histórico particular no caso referente aos estudos originais de Francis Galton, primo de Charles Darwin, devido a uma inferência incorreta que é feita a partir de suas observações. Galton avaliou a altura dos pais contra a altura dos filhos. O resultado de sua investigação é que filhos de pais altos tendem a ser altos, mas menores que seus pais, e que filhos de pais baixos tendem a ser também baixos, mas maiores que seus pais e, desta forma, a altura da população tenderia a convergir para a média. A falácia ocorre porque a seleção de observaçôes tomando seus extremos levaria naturalmente a essa tendência. Para uma discussão detalhada da Falácia de Galton veja Bliss (1999) e Cannon e Duck (2000). 
Friedman usa como exemplo o estudo de Baumol, Blackman e Wolff (1989) para elucidar essa questão. Esses autores calculam a regressão, para 16 países industrializados, entre a taxa de crescimento anual do período 1950 e 1970 contra o PIB por hora-trabalho em 1950. Os resultados dessas estimativas confirmam a hipótese de convergência, no sentido de que quanto menor a produtividade em 1950 mais rápido é o crescimento do país nesse período.

No entanto, como forma de avaliar a robustez desses resultados, Friedman sugere que o exercício fosse repetido excluindo da amostra os Estados Unidos e o Japão e substituísse a renda inicial pela terminal. Neste caso, verificou-se um fraco ajuste do modelo com tendência à dispersão e não convergência. Segundo ainda esse autor, flutuações aleatórias não persistentes na renda per capita poderiam levar a um coeficiente de regressão negativo, mesmo se a variância populacional da renda mostrasse tendência não decrescente.

Para Quah, o problema da Falácia de Galton pode ocorrer em estudos de convergência porque a variável renda não é considerada um processo de Markov. Os sinais dos coeficientes das regressões de convergência podem ser consistente apenas no caso em que se considere uma distribuição cross-section da renda invariante ao longo do tempo. De outro modo, estudos empíricos que apontam convergência podem estar, na realidade, apresentando um processo de divergência em curso.

Neste sentido, incorporando as preocupações de Quah, Mossi et alii (2003) evidenciam a existência de dois clusters espaciais no Brasil, um de baixa renda para o Nordeste e outro de alta renda para o Sudeste, considerando na análise o PIB per capita dos Estados brasileiros de 1939 a 1998. Além do mais, o estudo reforça a idéia da forte influência espacial na determinação do nível de renda, no sentido de que Estados com nível de renda mais elevado teriam mais chances de se tornarem prósperos. Resultados semelhantes são obtidos também em Andrade et alii (2004). Utilizando estimações via núcleo estocástico para os municípios brasileiros, considerando o período de 1970 a 1996, os autores constatam a formação de uma distribuição bimodal com dois clubes de convergência: o primeiro, com municípios das regiões Norte e Nordeste, e o segundo, com municípios do Sudeste, Sul e Centro-Oeste.

A importância desses dois estudos se sustenta no fato de eles contestarem os resultados tradicionais que comprovam a inexistência ou a fraca evidência de convergência entre municípios e Estados brasileiros. Eles sugerem que a hipótese de ausência de convergência verificada pode ser substituída pela idéia da bimodalidade na distribuição de renda per capita ou na formação de clubes de convergência regional no Brasil. É interessante notar que esses resultados se assemelham à tendência mundial, como discutido em Jones (1997). 
As novas evidências advindas de Mossi et alii (2003) e Andrade et alii (2004) reforçam mais ainda o debate sobre as políticas de redução dos desequilíbrios regionais no Brasil. Neste sentido, este artigo procura aprofundar a discussão investigando que variáveis poderiam ser responsáveis por tal polarização. Resultados importantes na literatura recente de crescimento econômico têm apontado o nível de escolaridade, a abertura comercial e a concentração de renda como algumas das variáveis significantes na determinação do nível de renda das economias. Ademais, assim como em Andrade et alii (2004), o efeito da vizinhança também é investigado, como a "nova geografia econômica"3 sugere.

Este artigo estuda os condicionantes do crescimento da renda per capita de Estados e municípios entre 1970 e 1990 utilizando a metodologia desenvolvida em Quah (1997), e encontra-se dividido da seguinte forma: na seção l são estimadas as densidades de distribuição de renda por meio do uso de núcleo gaussiano, para analisar a evolução das distribuições como um todo ao longo do período analisado. Na seção 2 são gerados núcleos estocásticos de Markov para períodos de transição de 10 e 20 anos, o que permitirá observar os movimentos das economias ao longo da distribuição. Os núcleos estocásticos condicionados são estimados na seção 3 e a última seção é dedicada às conclusões.

\section{EVOLUÇÃO DA DENSIDADE DE DISTRIBUIÇÃO DE RENDA}

Como discutido, ao se estimar uma regressão cross-section da taxa de crescimento em função da renda inicial o que se obtém, na verdade, é a informação do efeito médio da renda inicial no crescimento ou a correlação entre estas variáveis. Um ponto enfatizado em Durlauf e Quah (1998) é que tal fato é pouco informativo sobre o que acontece com o universo de economias analisadas no cross-section.

Uma forma de contornar esta limitação é analisar a distribuição intra-seccional da renda como um todo. Esta análise pode ser feita pela "discretização" do espaço de rendas, por meio da construção de histogramas, que permitem uma visualização gráfica das freqüências relativas. Na construção do histograma, as economias analisadas são agrupadas em intervalos de renda de tamanho fixo. Um problema existente na "discretização" de um espaço contínuo é que podemos obter resultados diferentes dependendo da origem ou do tamanho dos intervalos escolhidos.

3 Este termo é utilizado por Fujita, Krugman e Venables (1999) para descrever os modelos teóricos de determinação da concentração especial da produção desenvolvidos na obra citada. 
Para evitar as distorções produzidas pela "discretização" ${ }^{4}$ pode-se estimar uma densidade de distribuição pelo método de suavização por núcleo (kernel smoothing). $\mathrm{O}$ Gráfico 1 exibe um exemplo de duas densidades de renda dos países, estimadas para os períodos $t$ e $t+s$, em que se observa um movimento de divergência, levando a distribuição inicialmente unimodal no período $t$ a tornar-se bimodal em $t+s$.

\section{GRÁFICO 1 - EXEMPLO DA EVOLUÇÃO DA DENSIDADE DE RENDA DOS PAÍSES NO TEMPO}

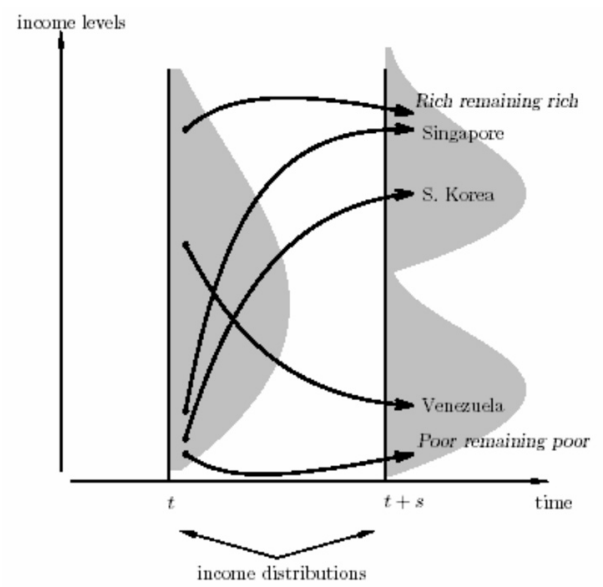

Nota: Gráfico retirado de Quah (1977).

O Gráfico 2 apresenta as densidades do PIB per capita relativo à média nacional, denotados a partir deste ponto como PIBr, dos Estados brasileiros ${ }^{5}$ de 1970 a 2000, estimadas via procedimento de suavização por núcleo gaussiano, ${ }^{6}$ anteriormente descrito. No eixo horizontal consta a escala do PIBr. Assim, o ponto 1,0 corresponde à média, 0,5 à metade da média, 2,0 ao dobro. $\mathrm{Na}$ análise destes gráficos, uma curva mais concentrada (leptocúrtica) em torno do ponto 1.0 indica uma maior convergência, enquanto uma curva mais achatada (platicúrtica) indica maior dispersão da rendas, portanto, maior divergência.

Esse mesmo gráfico exibe um processo de convergência entre os Estados brasileiros ${ }^{7}$ no período de 1970 a 2000, com a distribuição dos $\mathrm{PIBr}$ aumentando sua concen-

4 Para um exemplo veja Silverman (1986, p. 11).

5 Os dados de PIB, PIB per capita, população, escolaridade, desigualdade de renda foram obtidos no site do IPEADATA, na Internet. Os dados de comércio exterior foram obtidos do Ministério do Desenvolvimento, Indústria e Comércio (MDIC/SECEX).

6 As densidades e núcleos estocásticos foram estimados pelo programa TSRF, disponível gratuitamente na Internet no endereço http://econ.lse.ac.uk/staff/dquah/tsrf.html.

7 A análise do Gráfico 2 deve ser feita com relativa cautela em virtude do reduzido tamanho da amostra. Neste gráfico uma possível mudança no PIBr de um pequeno grupo de Estados é capaz de produzir alterações significativas na densidade estimada. Os resultados mais significativos dos Estados são os 
tração em torno da média nacional. Percebe-se, para 1970, que a maioria dos estados possuía PIBr ao redor 0,5, com um pequeno grupo separado dos demais apresentando PIBr ao redor de 2. Em 2000, os Estados passaram a formar um único bloco, sendo este movimento um indicativo de convergência.

\section{GRÁFICO 2 - DENSIDADE DO PIBr DOS ESTADOS BRASILEIROS}
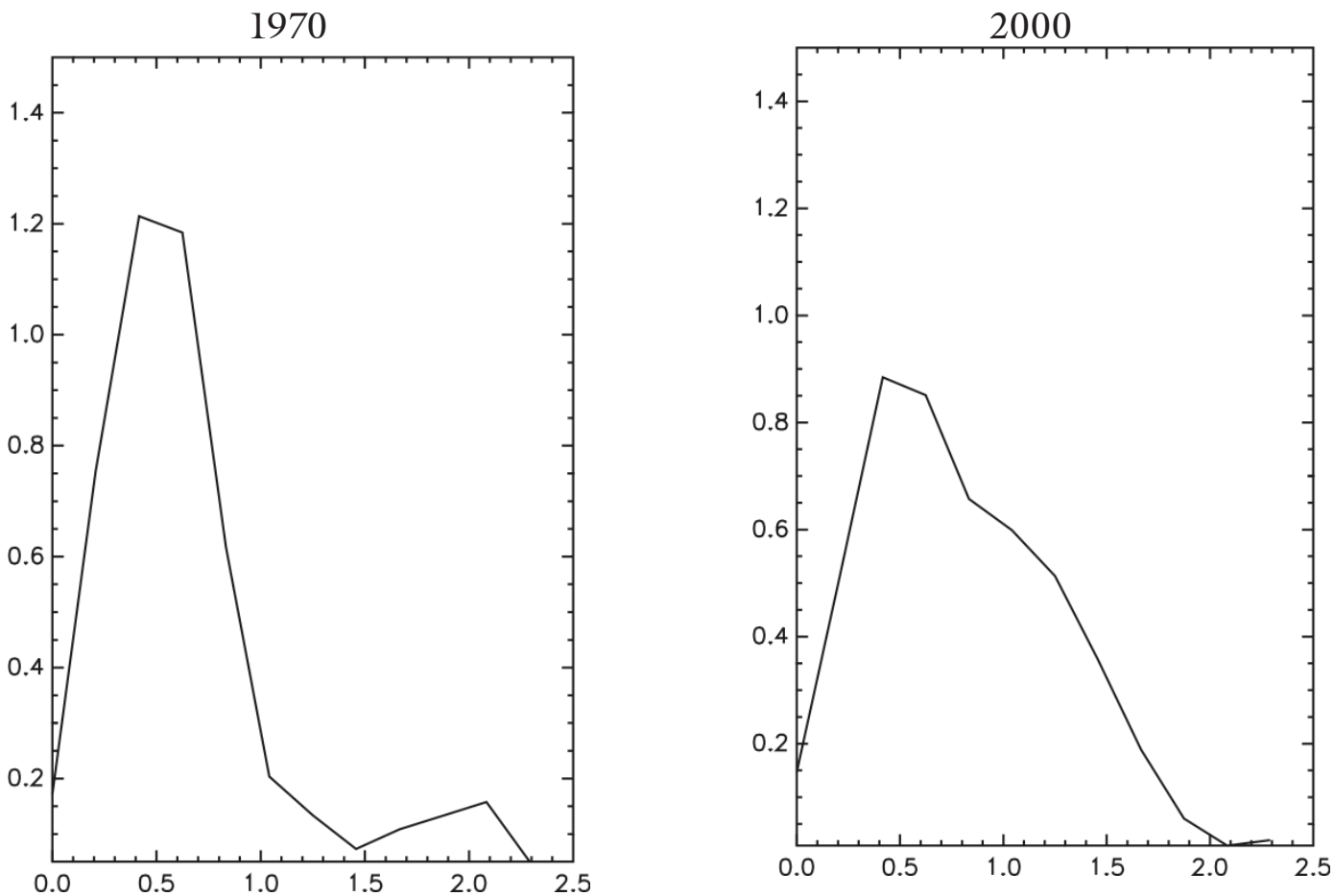

O Gráfico 3, relativo aos municípios, exibe uma redução na amplitude das rendas, causada pelo aumento do $\mathrm{PIBr}$ dos municípios ${ }^{8}$ mais pobres e redução do $\mathrm{PIBr}$ dos mais ricos, simultaneamente a uma transformação da distribuição de unimodal para bimodal, com a primeira moda situando-se ao redor de 0,3 e a segunda entre 0,6 e 0,8 da média nacional. Ressalte-se que este segundo movimento seria muito difícil de ser detectado por meio de uma regressão de $\beta$-convergência.

produzidos pelos núcleos estocásticos, nos quais são observadas 11 transições (1970 a 1990, 1971 a 1991, 1980 a 2000) para o mesmo cross-section de Estados, aumentado de forma expressiva a amostra analisada.

8 O PIB per capita dos municípios relativo aos anos 1970 e 1980 foi calculado a partir dos valores de PIB e população. Foram incluídos na amostra de municípios somente aqueles com dados para todos os anos analisados. 


\section{GRÁFICO 3 - DENSIDADE DO PIBr DOS MUNICÍPIOS BRASILEIROS}
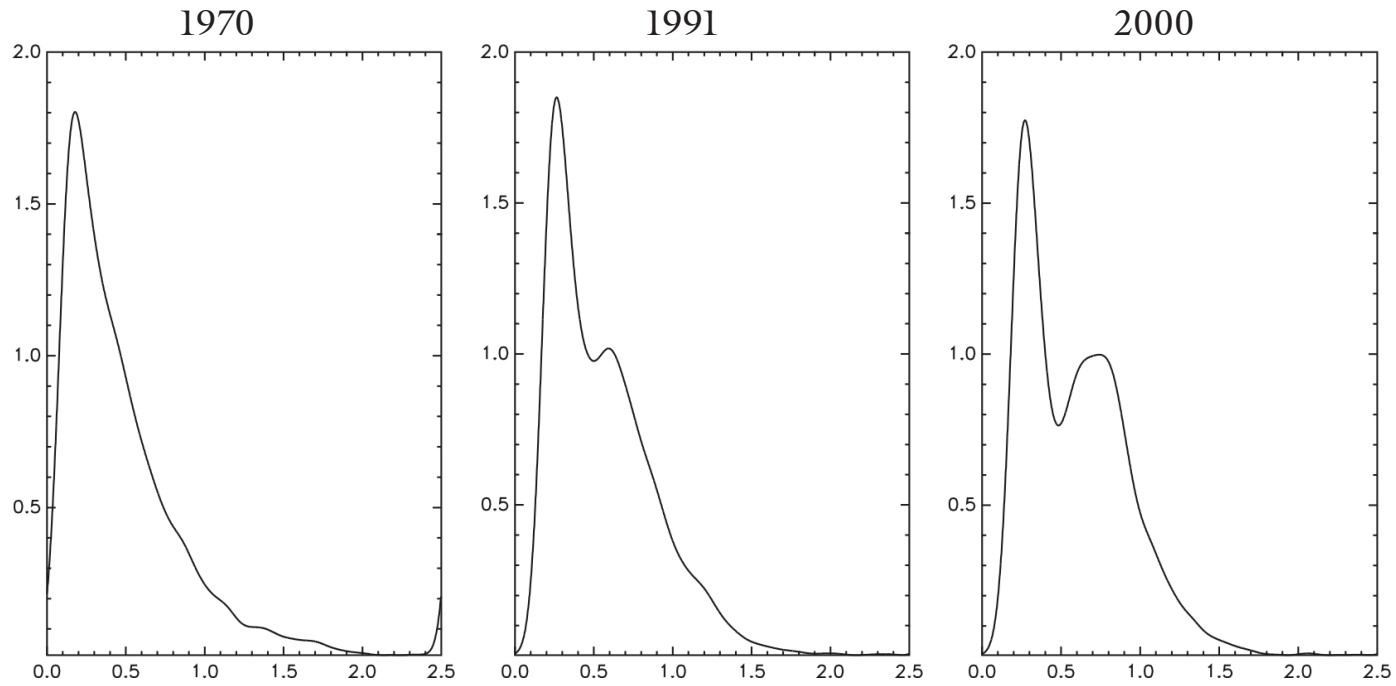

2. ANÁLISE DA DINÂMICA INTRADISTRIBUIÇÃO (NÚCLEO ESTOCÁSTICO)

\subsection{Conceito}

A análise da dinâmica intradistribuição pode ser feita por meio da "discretização" do espaço de rendas relativas, dividindo-o em $\mathrm{N}$ intervalos predeterminados. ${ }^{9}$ Esta "discretização", entretanto, pode produzir resultados diferentes, dependendo dos intervalos escolhidos, da mesma forma que o histograma pode produzir no caso unidimensional. Para evitar este problema, optou-se por seguir a metodologia desenvolvida em Quah (1997), que mantém os dados na forma contínua, fazendo com que o número intervalos (células) tenda ao infinito, e depois a um continumm. A matriz de transição tende, então, para um continumm de linhas e colunas, tornando-se um núcleo estocástico (stochastic kernel). Seguindo Quah, a definição formal do núcleo estocástico é a seguinte:

Seja o espaço de Estados subjacentes, dado pelo par $(\mathbb{R} \Re)$, linha real $\mathbb{R}$ conjuntamente com a coleção $\mathfrak{R}$ de seus conjuntos de Borel. Seja B o espaço de Banach de funções limitadas, finitamente aditivas, no espaço mensurável $(\mathbb{R} \Re)$ com norma de variação total dada por:

9 Este procedimento foi utilizado, por exemplo, em Quah (1993). 


$$
\forall \mu \in \mathrm{B}(\mathbb{R}, \Re):|\mu|=\sup \sum_{j}\left|\mu\left(A_{j}\right)\right|
$$

Em que o supremo é tomado sobre todo o conjunto finito $\left\{A_{j}: j=1,2, \ldots, n\right\}$ de partiçôes mensuráveis de $\mathbb{R}$ Distribuições empíricas em $\mathbb{R}$, as quais podem ser identificadas com medidas de probabilidade em $(\mathbb{R}, \mathfrak{R})$, que são, por sua vez, apenas elementos aditivamente contáveis em $(\mathbb{R} \Re)$, sendo atribuído o valor l para o espaço inteiro $\mathbb{R}$

Sejam $\mu$ e $v$ elementos de B, que são medidas de probabilidade em $(\mathbb{R}, \mathfrak{R})$. Um Núcleo Estocástico relacionando $\mu$ e $v$ é um mapeamento $\mathrm{M}_{(\mu, v)}:(\mathbb{R}, \Re) \rightarrow[0,1]$ satisfazendo:

a) $\forall y \in \mathbb{R}$ a restrição $\mathrm{M}_{(\mu, v)}(y,$.$) é uma medida de probabilidade;$

b) $\forall A \in \Re$, a restrição $\mathrm{M}_{(\mu, v)}(., A)$ é $\Re$-mensurável;

c) $\forall A \in \mathfrak{R}$, temos $\mu(A)=\int M_{(\mu, v)}(y, A) d v(y)$.

Em um período inicial, para um dado $y$, existe uma fração $d v(y)$ de economias com renda próxima a $y$. Se se contar todas as economias neste grupo cuja renda esteja subseqüentemente no subconjunto $\Re$-mensurável $A \subseteq \mathbb{R}$, tal contagem, quando normalizada para ser uma fração do número total de economias, será $\mathrm{M}_{(\mu, v)}(y, A)$.

Fixando $A$, ponderando a contagem $\mathrm{M}(y, A)$ por $d v(y)$, e somando sobre todos os possíveis $y$, isto é, calculando a integral $\int M(y, A) d \mathrm{n}(y)$, tem-se a fração das economias que terminam no estado $A$, independentemente de sua situação inicial. Se isto for igual a $\mu(A)$ para todos os subconjuntos mensuráveis $A$, então $\mu$ deve ser a medida associada com a distribuição subseqüente da renda.

Em outras palavras, o núcleo estocástico $M$ é uma descrição completa das transições do estado $y$ para qualquer outra porção do espaço de estados $\mathbb{R}$. A forma mais simples de se modelar a dinâmica da distribuição é por meio de um processo de Markov de $1^{a}$ ordem, que é análogo a um processo auto-regressivo de $1^{\mathrm{a}}$ ordem - AR(1).

\subsection{Estimação}

O Gráfico 4 exibe o núcleo estocástico para transições de 20 anos do PIBr dos estados brasileiros de 1970 a 2000. Para interpretá-lo, note que a partir de cada ponto no eixo 
denominado period $t$, estendendo-se ao longo do eixo period $t+20$, o núcleo estocástico corresponde a uma função densidade de probabilidade, que indica a probabilidade de um Estado possuir a renda final medida em $t+20$, condicionada à renda inicial medida em $t$. O Gráfico $4 \mathrm{~b}$ apresenta o mesmo resultado na forma de curvas de nível, como se fossem cortadas fatias horizontais no núcleo estocástico, de modo que as curvas mais centrais indicam uma probabilidade maior.

Alguns exemplos facilitam o entendimento. A massa do núcleo estocástico se concentrando ao longo do eixo diagonal é um indicativo de estabilidade nas rendas relativas dos Estados, ou seja, os pobres permanecem pobres e os ricos permanecem ricos. Por outro lado, se a concentração do núcleo estocástico for paralela ao eixo period $t$, isto mostra que, independentemente de suas rendas iniciais, os Estados apresentariam a mesma renda final, implicando convergência.

\section{GRÁFICO 4 - NÚCLEO ESTOCÁSTICO PARA TRANSIÇÃO DE 20 ANOS DO PIBr DOS ESTADOS BRASILEIROS (1970 A 2000)}

$4 \mathrm{a}$

Estados transicao $20 \cdot \operatorname{anos} \cdot(1970 \cdot a \cdot 2000)$

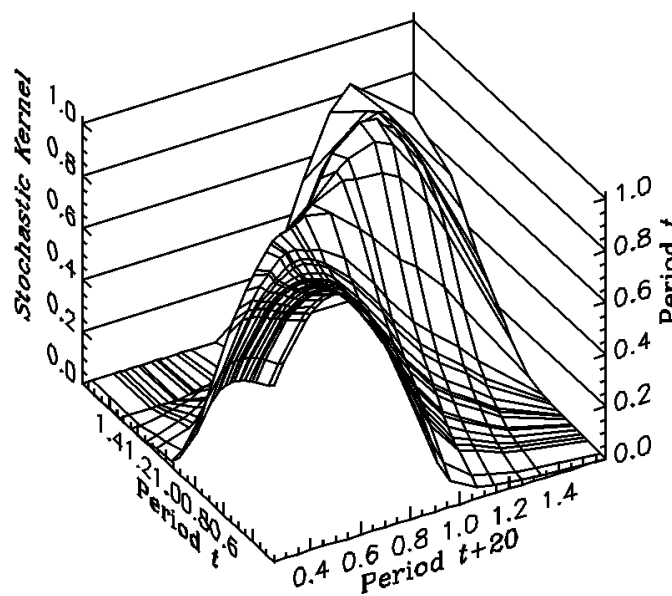

$4 \mathrm{~b}$

Estadostransicao $20 \cdot \operatorname{anos} \cdot(1970 \cdot a \cdot 2000)$

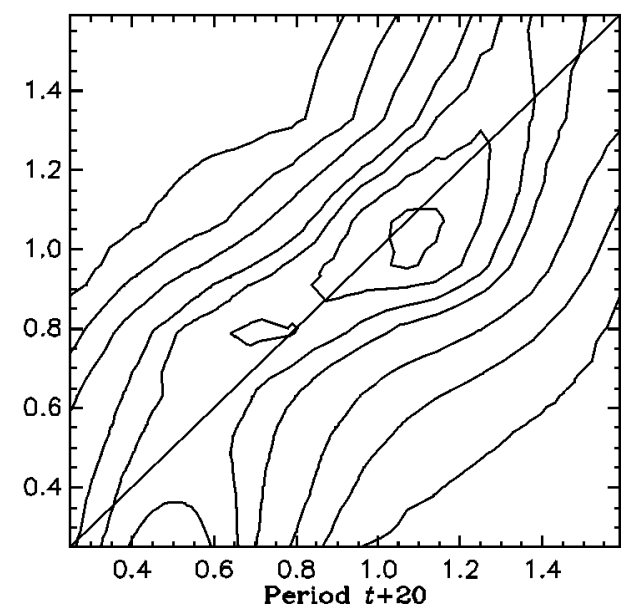

No Gráfico 4 pode-se distinguir o início da formação de dois clubes de convergência: o primeiro, composto por Estados considerados pobres, com renda inferior a 0,8 da renda nacional, representado pelos Estados do Nordeste e Norte, com exceção do Amazonas, mais Mato Grosso e Goiás; e o segundo grupo pelos Estados mais ricos, com renda acima da renda nacional, formado pelos Estados da região Sul, mais São Paulo, Rio de Janeiro, Espírito Santo e Amazonas.

Em termos de municípios, o Gráfico 5 exibe a convergência entre aqueles com $\mathrm{PIBr}$ entre 1,0 e 2,0 e menor que 0,3 . Ao mesmo tempo, é possível identificar uma leve 
divergência entre os municípios com renda entre 0,3 e 0,6 e uma dispersão dos municípios com renda superior a 2,0 que migraram para diversos estratos de renda do intervalo entre 0,5 a 2,0. ${ }^{10}$ Estes resultados, de forma geral, se assemelham àqueles obtidos em Mossi et alii (2003) e Andrade et alii (2004).

GRÁFICO 5 - NÚCLEO ESTOCÁSTICO PARA TRANSIÇÃO DE 20 ANOS DO PIBr DOS MUNICÍPIOS BRASILEIROS (1970 A 2000)

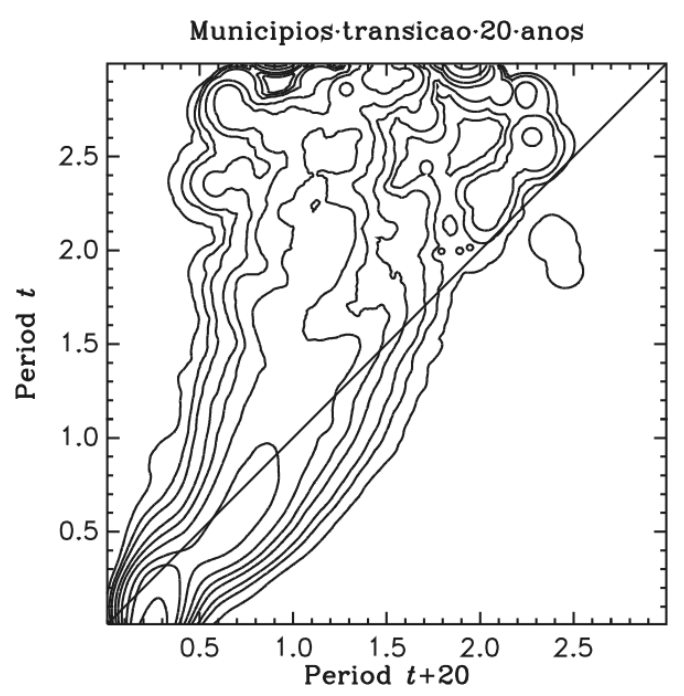

Para verificar a consistência dos resultados obtidos na distribuição bimodal do $\mathrm{PIBr}$ dos municípios (Gráfico 3) foi estimada a $\beta$-convergência ${ }^{11}$ somente para o grupo situado no intervalo de 0,3 a 0,6 da média nacional, que corresponde ao vale surgido entre as duas modas destas distribuições no período de 1991 a 2000. Os resultados apresentados na Tabela 1 confirmam o esperado: enquanto a regressão com os municípios situados no intervalo de 0,3 a 0,6 apresentou divergência ( $\beta$ positivo e significante ao nível de $1 \%$ ), a regressão com todos os municípios apresentou convergência ( $\beta$ negativo e significante ao nível de $1 \%$ ).

10 Os resultados relativos aos municípios com PIBr superior a 2 são pouco significativos devido ao reduzido número de municípios compreendidos neste intervalo.

11 Laurini e outros (2003) optaram por utilizar o teste de multimodalidade via bootstrap. Neste artigo optou-se por utilizar a $\beta$-convergência por se tratar de uma metodologia vastamente utilizada para análise de convergência e para mostrar como pode ser enganoso tirar conclusóes somente a partir do resultado da regressão na amostra completa, demonstrando, dessa forma, a utilidade da estimação de densidades e núcleos estocásticos. 
TABELA $1-\beta-C O N V E R G E \hat{E N C I A ~ E N T R E ~ O S ~ M U N I C I ́ P I O S ~(P E R I ́ O D O ~} 1991$ A 2000)

\begin{tabular}{lcc}
\hline Amostra utilizada & Coeficiente $\beta$ & Estatística t \\
\hline Todos os municípios & $-0,13$ & $(-13,19)$ \\
Municípios com $\mathrm{PIBr}_{91}<0,3$ & $-0,92$ & $(-9,60)$ \\
Municípios com $0,3 \leq \mathrm{PIBr}_{91}<0,6$ & 0,50 & $(7,11)$ \\
Municípios com $\mathrm{PIBr}_{91} \geq 0,6$ & $-0,22$ & $(-13,23)$ \\
\hline
\end{tabular}

\section{TRANSIÇÕES INTRADISTRIBUIÇÃO CONDICIONADAS}

Um importante ponto na discussão, e que ainda não foi tratado na literatura no Brasil usando essa metodologia, é procurar identificar os principais fatores responsáveis pela formação dos clubes de convergência, tanto em nível municipal como estadual. Neste sentido, para identificar as forças que governam a evolução da distribuição de renda entre as unidades territoriais utilizam-se esquemas de condicionamentos como propostos em Quah (1997). O que se busca com o condicionamento é um cálculo computacional que ajude a entender a lei de movimento da distribuição como um todo. Da mesma forma que os núcleos estocásticos quantificam a evolução da distribuição ao longo do tempo, os condicionantes descrevem como um conjunto de variáveis pode alterar a distribuição intra-seccional da renda entre as economias.

Definição de um Esquema de Condicionamento: Para uma coleção de economias J, um esquema de condicionamento $S$ é uma coleção de triplas, uma para cada economia $\ell$ em J no instante t, com cada tripla consistindo:

a) $\mathrm{J}_{\ell}(\mathrm{t})$ um subconjunto de $\mathrm{J}$;

b) $\pi_{\ell}(\mathrm{t})$ um conjunto de pesos probabilísticos em $\mathrm{J}$, nunca positivos fora de $\mathrm{J}_{\ell}(\mathrm{t})$;

c) $\tau_{\ell}(\mathrm{t})$ um lag inteiro.

$\mathrm{J}_{\ell}(\mathrm{t})$ é a coleção de economias associadas com $\ell$ em t. Os pesos $\pi_{\ell}(\mathrm{t})$, que somente são positivos em $J_{\ell}^{\prime}(t)$, determinam a importância relativa de diferentes economias pertencentes a J', $(\mathrm{t})$ na evolução da economia $\ell$ em t. Por fim, $\tau_{\ell}(\mathrm{t})$ é um lag de tempo que indica o intervalo no qual os eventos nas economias em $\mathrm{J}_{\ell}^{\prime}(\mathrm{t})$ afetam $\ell$.

Se $\mathrm{Y}=\left\{\mathrm{Y}_{\ell}(\mathrm{t}): \ell\right.$ em $\mathrm{J}$ e $\left.\mathrm{t} \geq 0\right\}$ denotar as observações originais das rendas per capita relativas, define-se a versão condicional $Y^{c}=\frac{Y}{S}$ por: 


$$
Y_{\lambda}^{c}(t) \equiv \frac{Y_{\lambda}(t)}{\sum_{j \in J^{\prime}(t)} \pi_{j}(t) Y_{j}\left(t-\tau_{\lambda}(t)\right)}
$$

A renda condicionada, $Y^{c}$, corresponde à renda per capita de $\ell$ relativa às das outras economias de $J^{\prime}$, apropriadamente ponderada.

Deve estar claro que ao se analisar as densidades condicionadas é preciso verificar se o condicionamento pela variável escolhida provoca um aumento na concentração da distribuição ao redor de seu ponto médio (convergência) quando comparada à densidade não-condicionada.

Considere, por exemplo, a situação em que a densidade das rendas dos municípios condicionadas pelo nível de escolaridade apresenta-se mais concentrada em torno da média do que a densidade das rendas não-condicionadas. Neste caso, municípios com os mesmos indicadores de anos de estudos possuiriam renda mais próxima, e desta forma ter-se-ia uma evidência favorável à hipótese de convergência condicionada ao nível de escolaridade.

Por outro lado, se as densidades condicionadas apresentarem o mesmo padrão das densidades não-condicionadas, isto seria uma evidência de ausência de correlação entre a variável condicionante e a renda. A idéia é que se se agrupasse aleatoriamente nossa amostra de municípios por uma variável qualquer não relacionada à renda (por exemplo, agrupar os municípios pela primeira letra de seus nomes) seria bastante provável que a densidade condicionada a essa variável se apresentasse bastante semelhante à não-condicionada.

A interpretação dos núcleos condicionados segue a mesma lógica dos núcleos nãocondicionados anteriormente exposta. Dessa forma, se a massa do núcleo estocástico se concentrar ao longo do eixo diagonal, isto indica que o condicionamento escolhido não produz alteração significativa na distribuição, ou seja, não seria uma boa explicação para sua forma; se o núcleo estocástico se concentrar paralelo ao eixo Period $t$, isto indicaria que, quando ponderada pelo fator condicionante escolhido, as rendas convergiriam, isto é, o condicionamento produz uma boa explicação para a divergência de rendas observadas na distribuição não condicional, ou, ainda, a heterogeneidade de renda desaparece quando condicionada àquele fator.

Como já destacado anteriormente, serão utilizadas na próxima seção as variáveis localização geográfica, nível de escolaridade, abertura ao comércio internacional e desigualdade de renda para testar se elas são relevantes na formação dos núcleos estocásticos condicionados. 


\subsection{Condicionamento pela Localização Geográfica}

A importância dos fatores geográficos para o crescimento econômico tem ganho relativo espaço na literatura nos últimos anos. Dentre os trabalhos mais relevantes na área, Fujita, Krugman e Venables (1999) procuram mostrar como os fatores geográficos podem ter alguma influência na taxa de crescimento de uma economia. Por meio do que se convencionou chamar de a "nova economia geográfica", utilizam-se modelos com retornos crescentes de escala, economias de aglomeração, custos de transporte e diferenciação de produtos para explicar como a organização de uma atividade econômica heterogênea num determinado espaço geográfico pode ser importante.

Neste artigo foram efetuados três tipos de condicionamentos pela localização geográfica: no primeiro, os Estados foram agrupados de acordo com a região geográfica do País a que pertence, tendo sido atribuído o mesmo peso a todos os membros do grupo; no segundo, pelos vizinhos geográficos, mesmo que Estados que façam fronteira possam pertencer a regióes geográficas distintas. Neste caso, foi utilizado como fator de ponderação o inverso da distância rodoviária entre as capitais dos Estados. No terceiro esquema de condicionamento os Estados foram agrupados segundo suas latitudes. O critério de seleção para pertencer a essa categoria foi a distância máxima de cinco graus de latitude entre as capitais dos Estados, tendo sido utilizado como fator de ponderação o inverso da diferença de latitude entre as capitais.

Embora estas três formas de condicionamento (Gráficos 6a a 6c) apresentem maior convergência do que a densidade não-condicionada (Gráfico 2), somente os condicionamentos à região (com desvios padrão de $\sigma_{1970}=0,38$ e $\left.\sigma_{2000}=0,29\right)$ e aos vizinhos geográficos $\left(\sigma_{1970}=0,39\right.$ e $\left.\sigma_{2000}=0,28\right)$ apresentaram convergência crescente ao longo do período, enquanto o condicionamento à latitude apresentou desvio padrão constante no período analisado $\left(\sigma_{1970}=0,41\right.$ e $\left.\sigma_{2000}=0,41\right)$. Esta crescente convergência de renda per capita intra-regional é compatível com a hipótese de clubes de convergência regional ou localmente distribuídos. 
GRÁFICO 6 - DENSIDADE DO PIBr DOS ESTADOS BRASILEIROS CONDICIONADA À LOCALIZAÇÃO GEOGRÁFICA

GRÁFICO 6A - REGIÃO GEOGRÁFICA
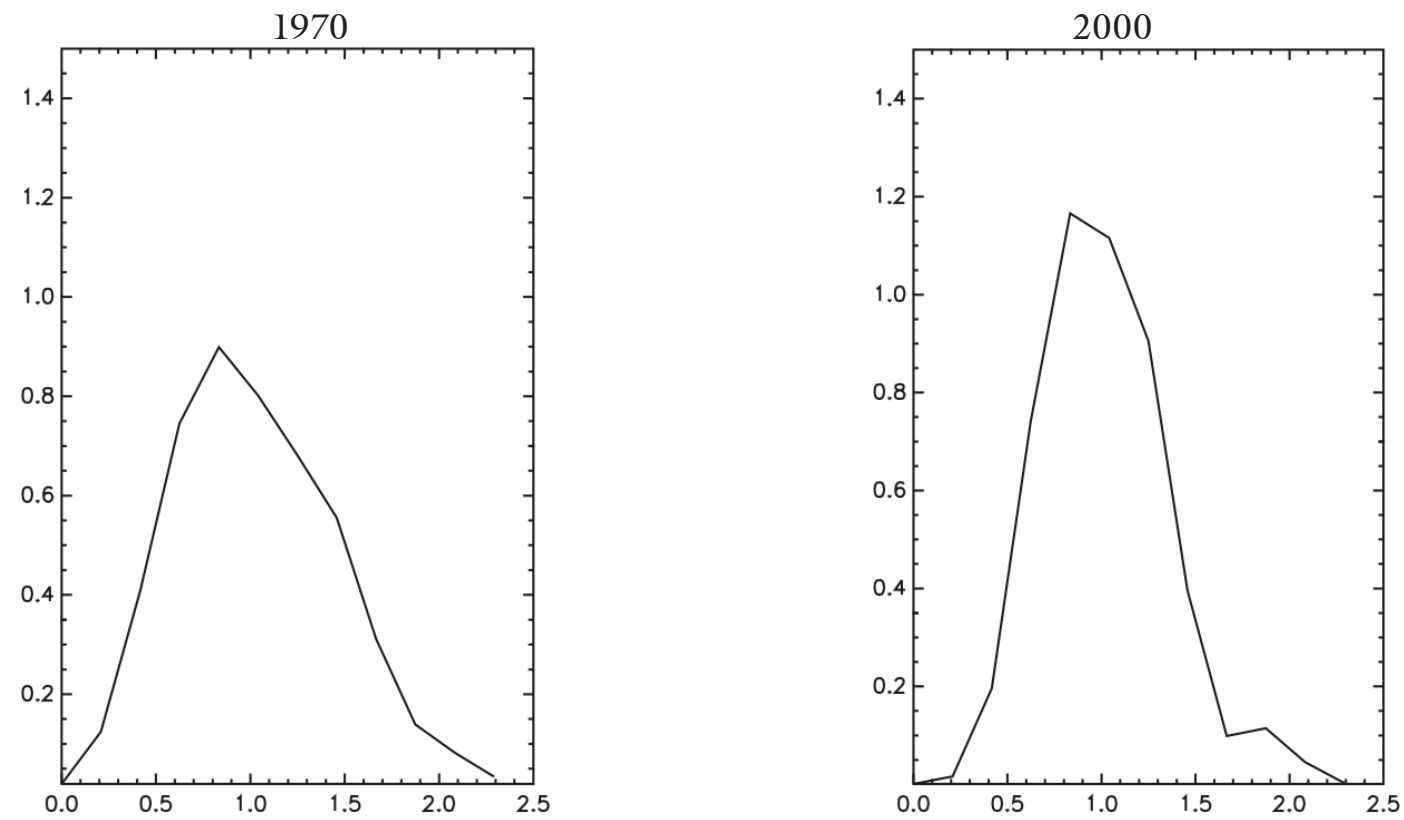

GRÁFICO 6B - VIZINHOS GEOGRÁFICOS
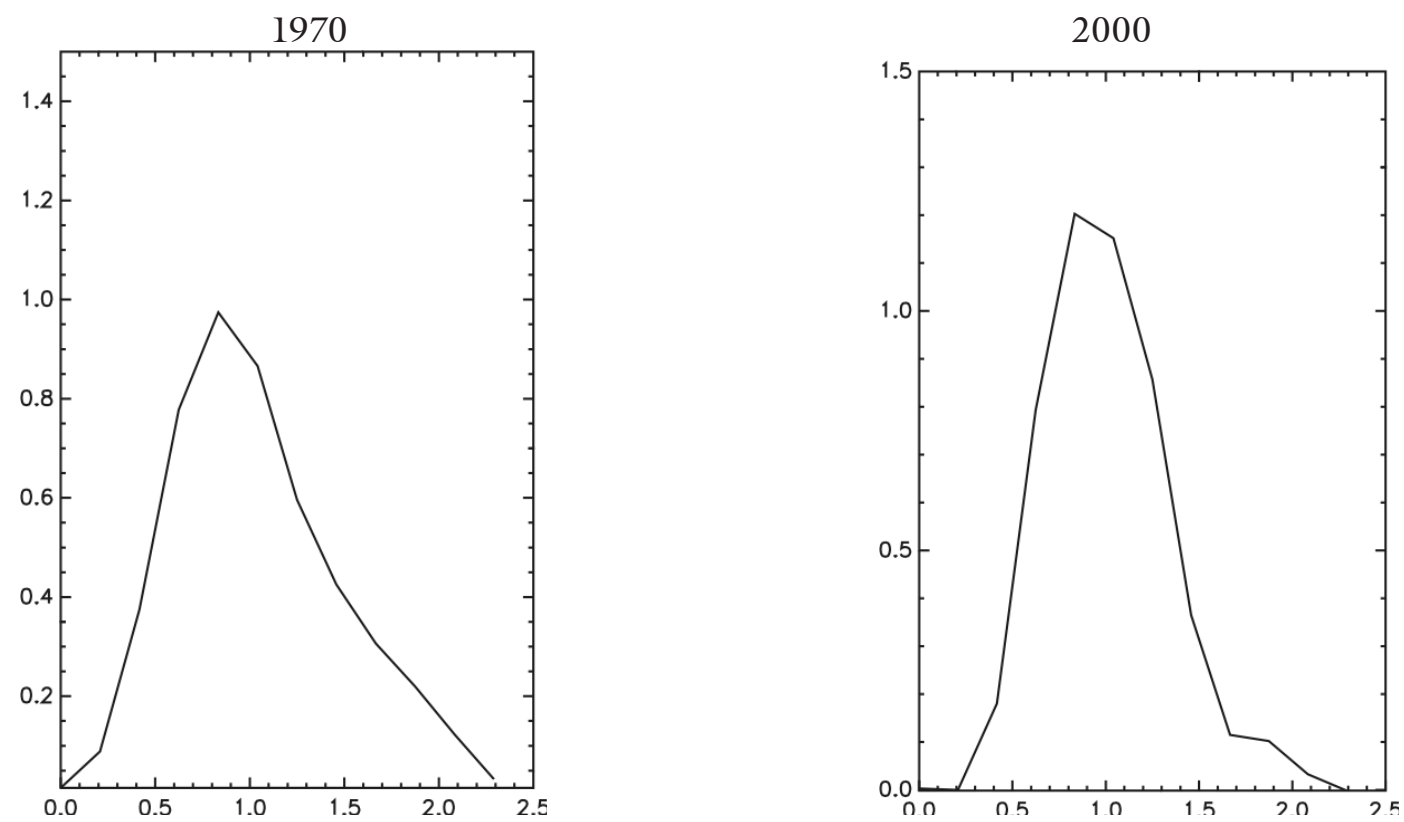

Estud. econ., São Paulo, 37(1): 71-100, jan-mar 2007 

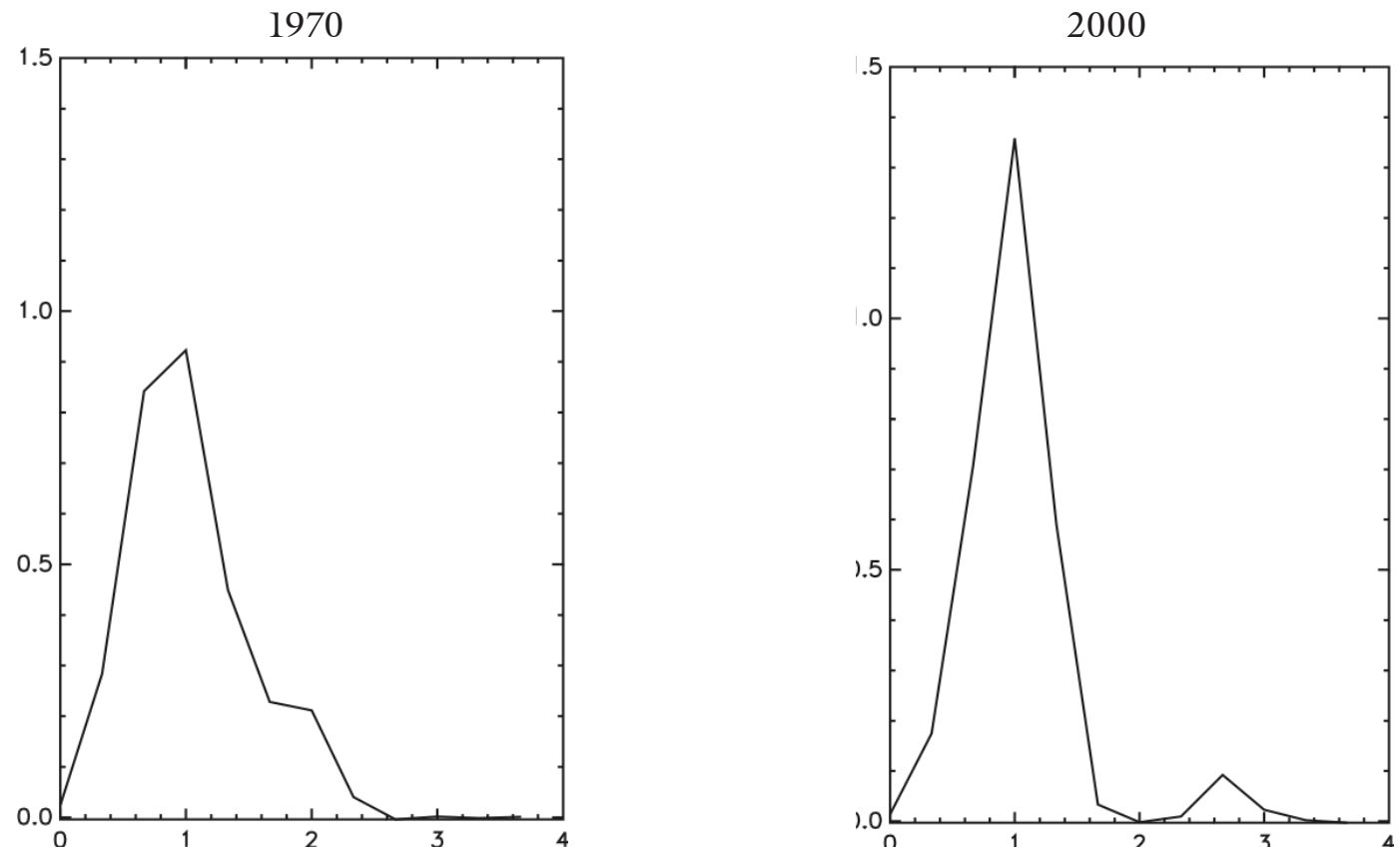

As densidades dos $\mathrm{PIBr}$ dos municípios condicionados à localização geográfica (Gráficos 7a a 7c) apresentam as seguintes características: aumento da convergência em relação à densidade do PIBr não-condicionado (Gráfico 3); aumento progressivo da convergência ao longo do período analisado; e aumento da convergência ao se reduzir o espaço de condicionamento (de região para Estado). Esta forma de condicionamento também removeu a bimodalidade existente na distribuição não-condicionada, reforçando a idéia da existência de fortes indícios de convergência condicionada à localização geográfica. 
GRÁFICO 7 - DENSIDADE DO PIBr DOS MUNICÍPIOS BRASILEIROS CONDICIONADA À LOCALIZAÇÃO GEOGRÁFICA

GRÁFICO 7A - REGIÃO GEOGR ÁFICA

1970

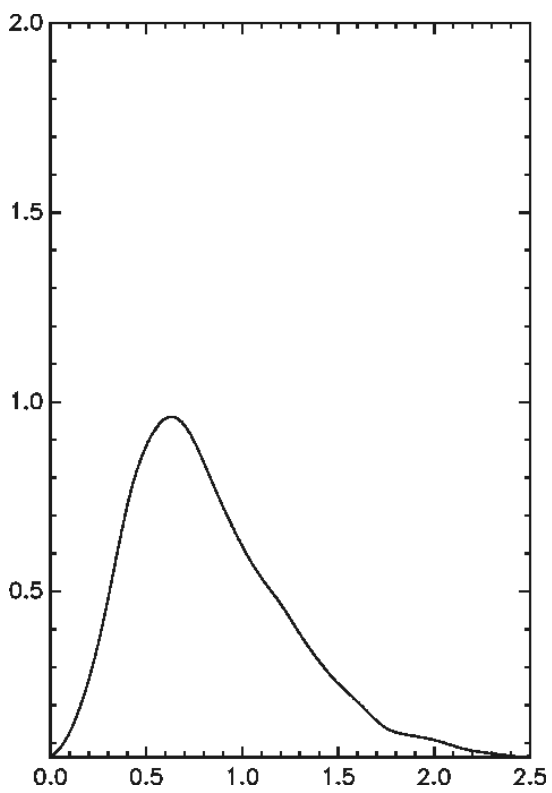

GRÁFICO 7B-ESTADO

1970

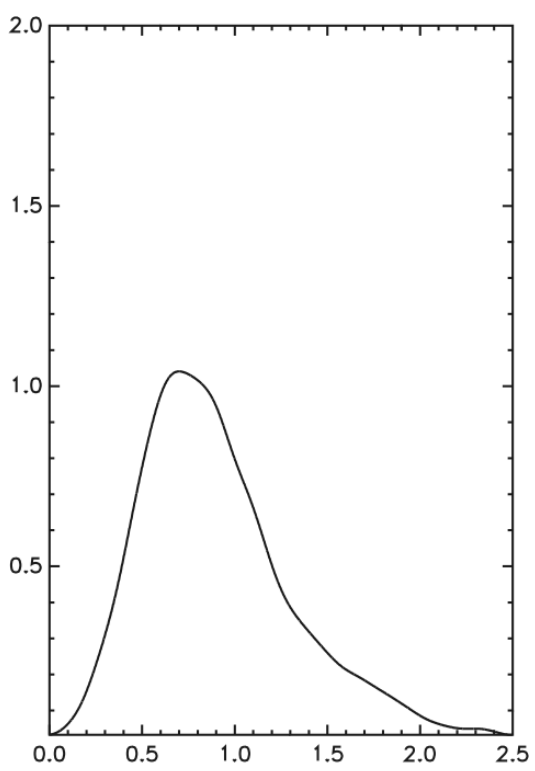

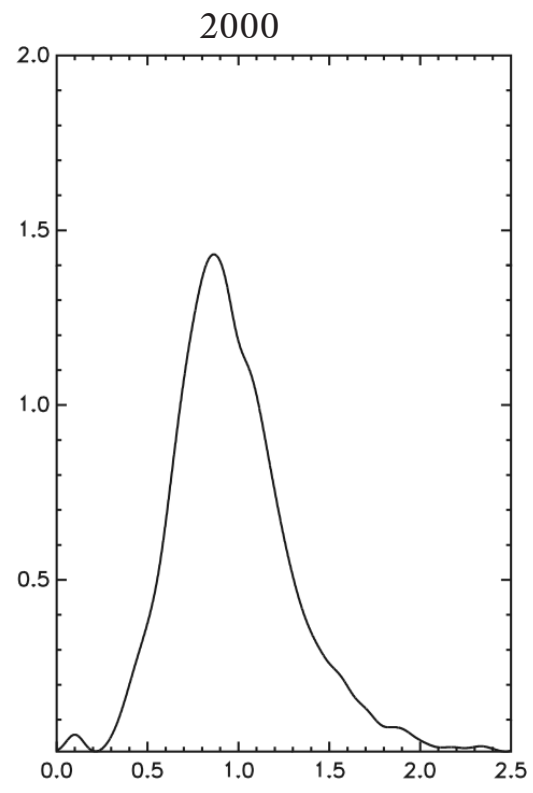

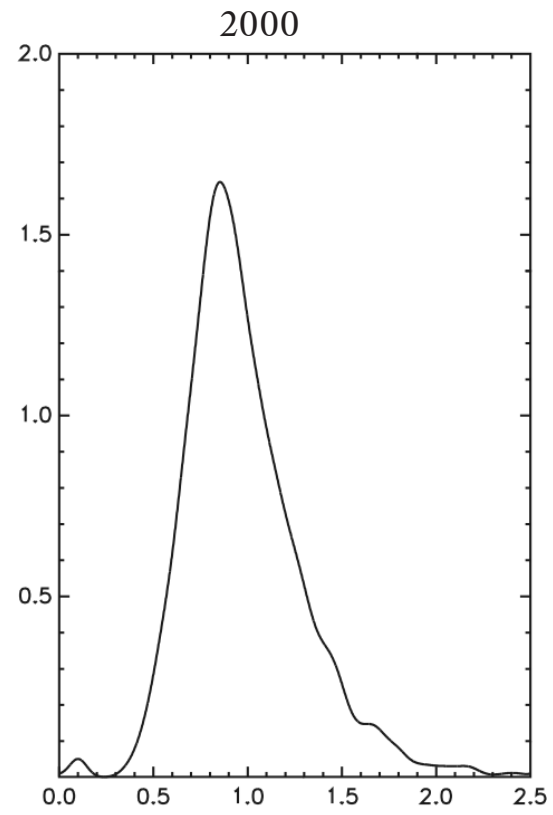

Estud. econ., São Paulo, 37(1): 71-100, jan-mar 2007 

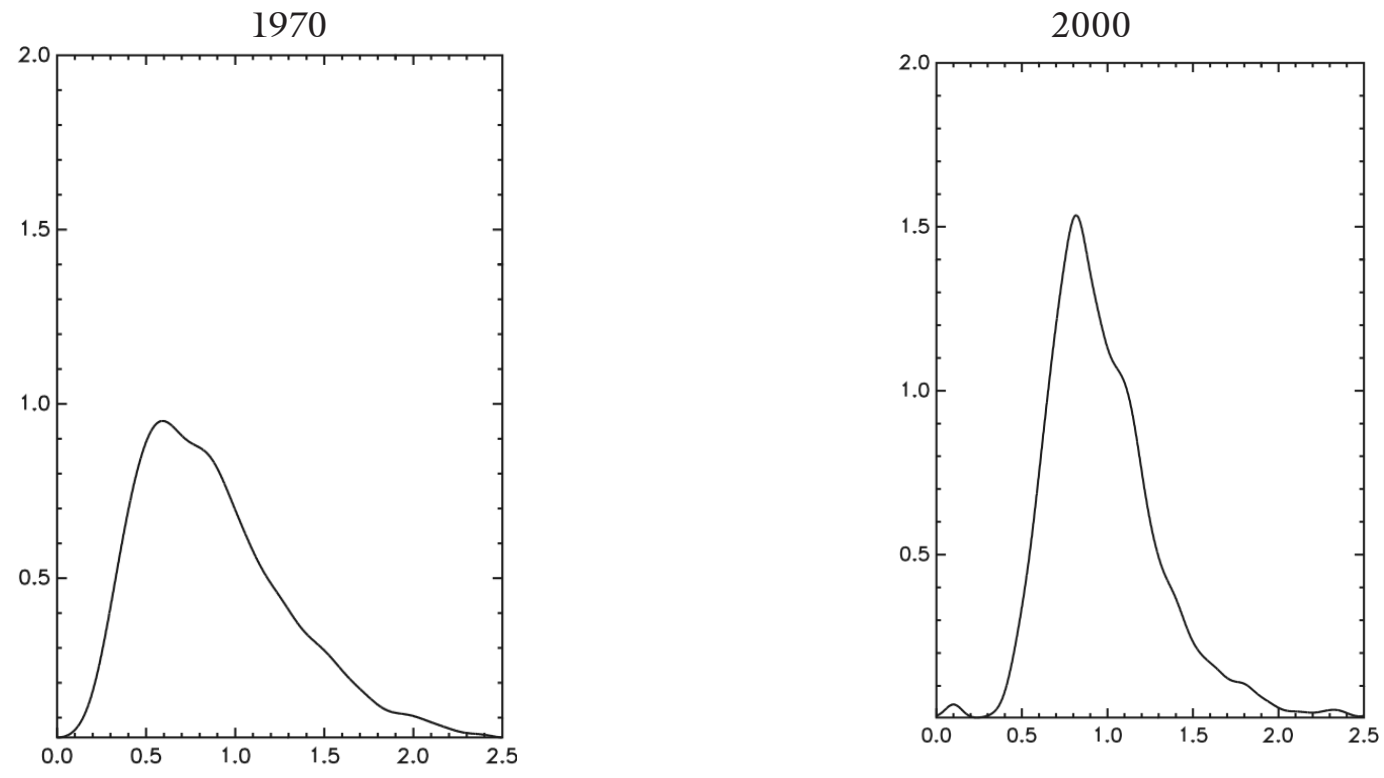

Os Gráficos 6 e 7 mostram que a principal forma pela qual a localização geográfica possa afetar os PIBs per capita seria por meio de canais relacionados à noção de proximidade, seja via spillovers de conhecimento, efeitos de escala ou proximidade de centros produtores e consumidores, e provavelmente não mediante canais relativos à latitude, como o clima.

Os Gráficos 8a e 8b, que apresentam núcleos estocásticos significativamente verticais, também apontam que a localização geográfica é um fator importante na explicação das diferenças de PIB entre Estados e municípios no Brasil. O Gráfico 8b exibe ainda um padrão no qual aqueles municípios com renda acima de 3 vezes à média do Estado foram divididos em dois grupos com tendências distintas: um grupo sofreu uma queda significativa de renda relativa, deslocando-se para o intervalo entre 1 e 2 , enquanto o outro manteve sua renda relativa. 
GRÁFICO 8 - NÚCLEOS ESTOCÁSTICOS CONDICIONADOS À LOCALIZAÇÃO GEOGRÁFICA

$8 A-P I B r$ DOS ESTADOS

CONDICIONADO AOS VIZINHOS

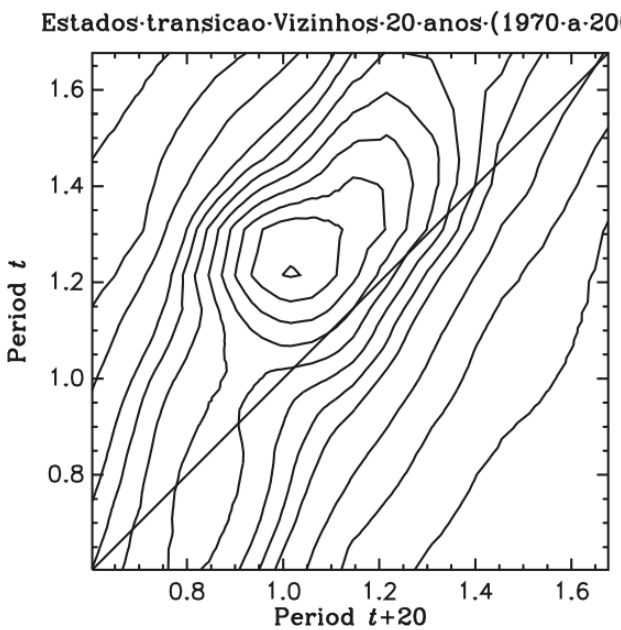

$8 B$ - PIBr DOS MUNICÍPIOS CONDICIONADO AOS ESTADOS

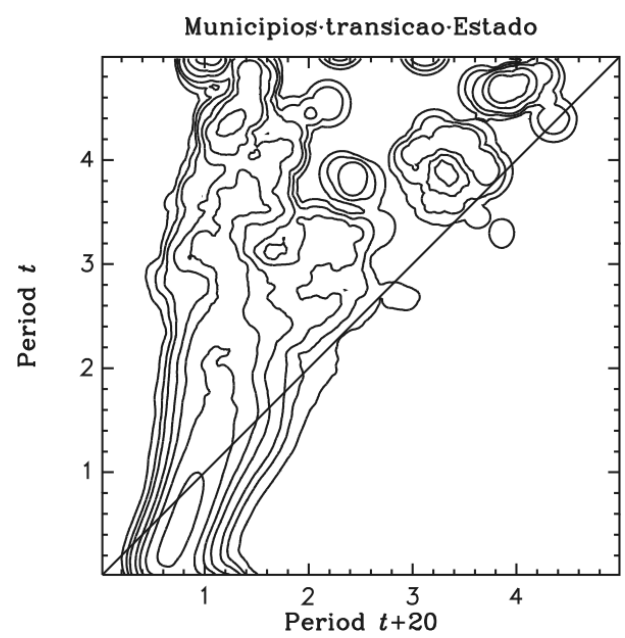

\subsection{Condicionamento por Capital Humano}

A importância do capital humano no processo de crescimento e desenvolvimento econômico tem sido amplamente documentada pela literatura. Lucas (1988) contribuiu para revigorar a teoria do crescimento mostrando como o capital humano pode gerar crescimento endógeno numa economia.

A literatura, tanto teórica como empírica, tem sido pródiga em mostrar que diversos são os mecanismos pelos quais a educação pode contribuir para o aumento do nível da renda per capita de uma economia: aumento na produtividade dos indivíduos, geração de externalidades positivas nos agentes econômicos, maior capacidade de gerar e absorver novas tecnologias, efeitos positivos sobre as instituições, e redução dos incentivos aos desvios sociais. ${ }^{12}$

12 Para um survey da literatura sobre a contribuição do capital humano, veja Johannes Hers (1998). 
O Gráfico 9, que exibe a evolução da densidade de PIBr dos Estados ${ }^{13}$ condicionado aos anos de estudo da população adulta no início do período, ${ }^{14}$ sinalizou convergência condicionada ao nível de escolaridade, apresentando distribuição mais concentrada (leptocúrtica) em torno do ponto médio do que a distribuição não-condicionada (Gráfico 2), e desvio padrão baixo e reduzindo-se ao longo do período de 0,26 para 0,15 . O núcleo estocástico condicionado aos anos de estudo (Gráfico 10) apresentou alta convergência, particularmente no intervalo de PIBr até 1,2. Pode-se perceber, por meio da análise conjunta dos Gráficos 9 e 10, que o aumento da concentração da densidade ao redor da média foi produzido pelo deslocamento de parte dos Estados com PIBr inferior a 0,5 e entre 1,0 e 1,2 em direção à média, remanescendo um pequeno grupo de Estados com PIBr por volta de 1,2.

\section{GRÁFICO 9 - DENSIDADE DO PIBr DOS ESTADOS BRASILEIROS CONDICIONADA AOS ANOS DE ESTUDO DA POPULAÇÃO ADULTA}
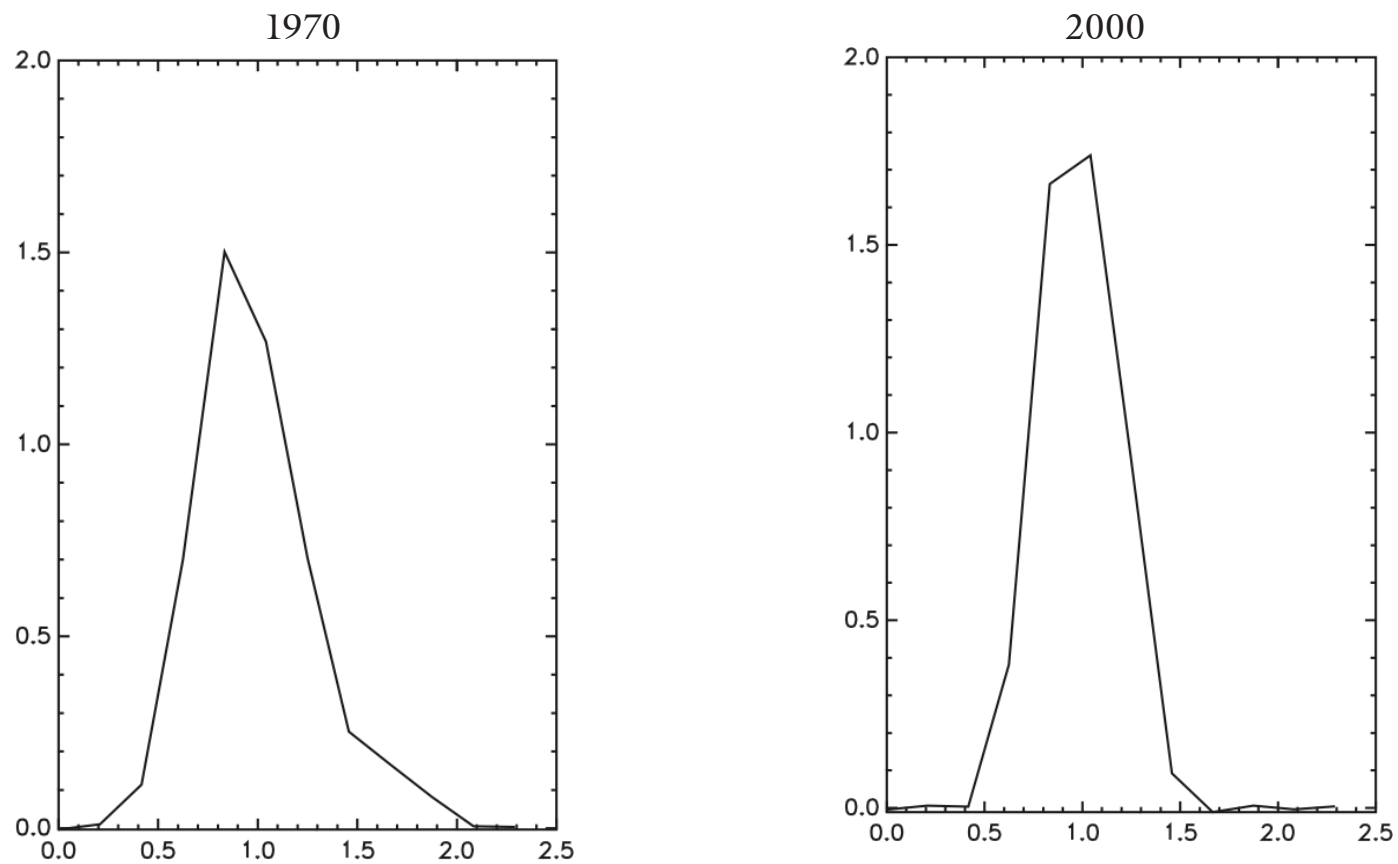

13 O condicionamento por capital humano dos Estados foi realizado com uma amostra reduzida, tendo sido excluídos os Estados da região Norte em decorrência de seus dados de escolaridade serem mensurados somente nas áreas urbanas, o que tornaria a comparação com os demais Estados distorcida.

14 Para evitar a endogeneidade entre escolaridade e crescimento, utilizou-se sempre a escolaridade do início do período de condicionamento. 
GRÁFICO 10 - NÚCLEO ESTOCÁSTICO DO PIBr DOS ESTADOS CONDICIONADOS Aे ESCOLARIDADE

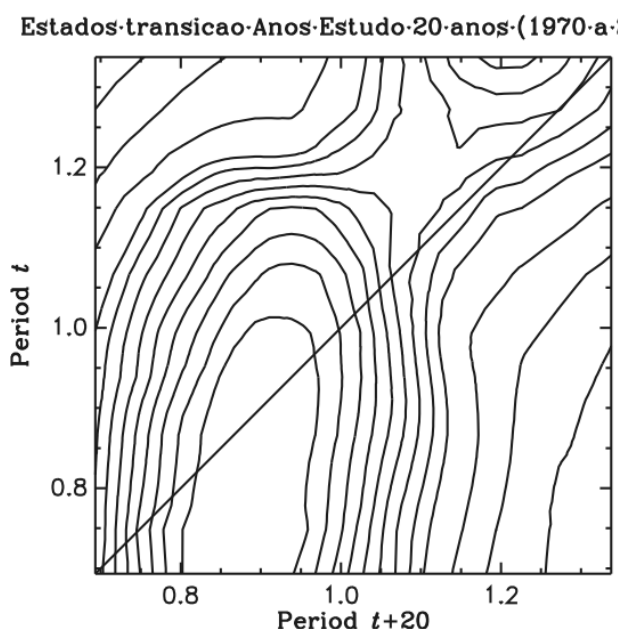

As densidades de PIBr condicionadas aos anos de estudo dos municípios (Gráfico 11) apresentam-se mais leptocúrticas do que as densidades incondicionadas (Gráfico 3). Estas densidades são unimodais e apresentam freqüência máxima crescente ao longo do período analisado, indicando convergência condicionada à escolaridade. $\mathrm{O}$ núcleo estocástico condicionado aos anos de estudo (Gráfico 12) apresentou expressiva convergência, com sua massa concentrando de forma paralela ao eixo vertical.

\section{GRÁFICO 11 - DENSIDADE DO PIBr DOS MUNICÍPIOS BRASILEIROS CONDICIONADA AOS ANOS DE ESTUDO DA POPULAÇÃO ADULTA}
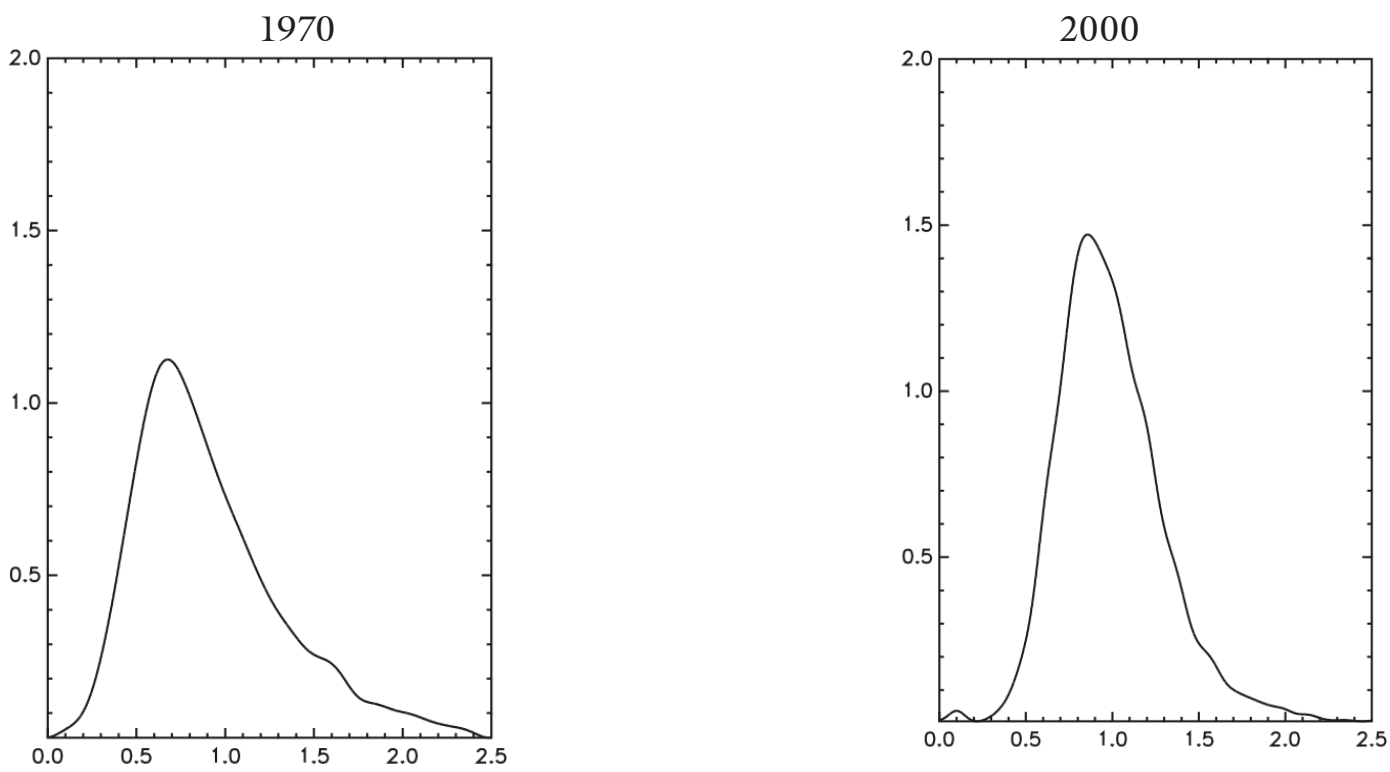


\section{GRÁFICO 12 - NÚCLEO ESTOCÁSTICO DO PIBr DOS MUNICÍPIOS CONDI- CIONADO À ESCOLARIDADE}

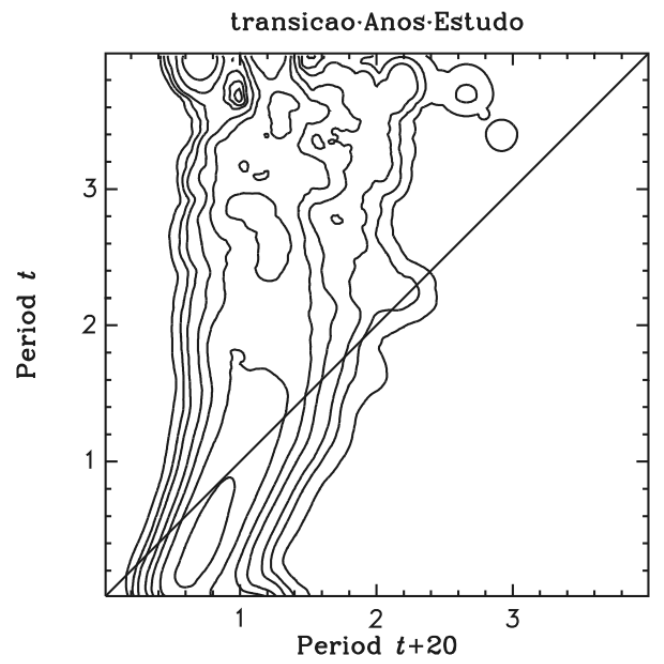

\subsection{Condicionamento pela Abertura Comercial}

Um outro condicionante na formação de clubes de convergência estaria relacionado ao grau de exposição de determinada economia ao comércio internacional. Neste aspecto, não existe consenso na literatura sobre se economias mais integradas ao comércio internacional tenderiam a crescer mais rápido. Uma visão positiva desse efeito estaria centrada no modelo ricardiano estático de vantagens comparativas, sem imperfeições de mercado, em que a maior abertura de uma economia ao comércio internacional aumentaria o nível de seu PIB real e não interferiria na taxa de crescimento de longo prazo.

Nos modelos de crescimento endógeno, a presunção é de que menores restrições ao comércio podem favorecer o crescimento da economia mundial como um todo. No entanto, como visto no modelo de vantagens comparativas dinâmicas de Grossman e Helpman (1991, cap. 7), determinados países podem apresentar uma redução no crescimento se num ambiente de comércio livre forem levados a se especializar em setores da economia nos quais os avanços tecnológicos estejam parcialmente exauridos ou sujeitos a retornos decrescentes.

Do ponto de vista empírico, diversos estudos, como de Dollar (1992), Edwards (1998), Frankel e Romer (1999), têm apontado uma correlação positiva entre abertura comercial e crescimento econômico. Por outro lado, Rodriguez e Rodrik (2000) contestam esses estudos, afirmando que muitos dos indicadores de abertura utilizados eram imprecisos ou eram altamente correlacionados com outras fontes de baixo 
desempenho econômico, de modo que não se poderia concluir se abertura estimula o crescimento.

Na estimação desta variável no esquema de condicionamento foi utilizada como índice de abertura comercial a razão do fluxo comercial (importações mais exportações) sobre o PIB dos Estados. ${ }^{15}$ Pode-se verificar pelo Gráfico 13 que a densidade do PIBr dos Estados condicionada à abertura comercial permaneceu praticamente inalterada ao longo de todo o período, com baixa concentração em torno da média. No Gráfico 14 verifica-se que o núcleo estocástico advindo deste condicionamento distanciou-se muito pouco da linha diagonal. Estes fatos indicam que a abertura comercial não pode ser considerada como um fator determinante na explicação das disparidades de rendas observadas. No entanto, deve-se deixar claro que o tamanho da amostra utilizada pode ser um elemento restritivo dessa conclusão.

\section{GRÁFICO 13 - DENSIDADE DO PIBr DOS ESTADOS CONDICIONADA À ABER- TURA COMERCIAL}
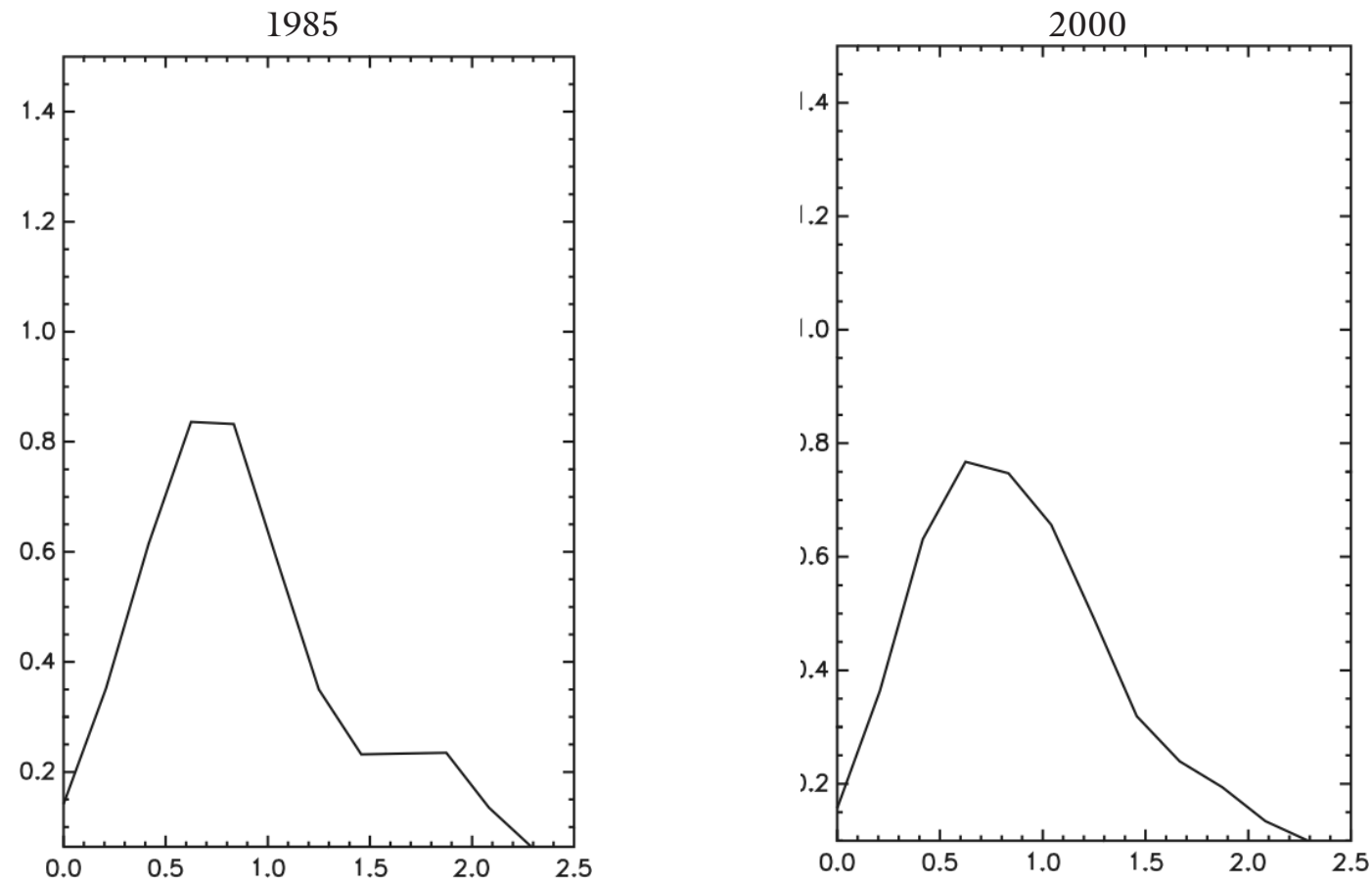

15 Com respeito à definição de abertura, embora ela pareça teoricamente simples, existe muita controvérsia na definição de uma medida que seja empiricamente correta, uma vez que uma taxa verdadeira de proteção deve refletir uma complicada combinação de ferramentas de política de comércio, incluindo aí um grande limite de barreiras institucionais. Para o propósito deste artigo, como se necessita de uma medida que capte o grau de integração comercial dos Estados brasileiros, as medidas utilizadas são mais adequadas que a incidência de barreiras tarifárias e não-tarifárias, porquanto ela se apresenta de forma semelhante para todos os Estados. A dificuldade de obtenção desse indicador para os municípios inviabiliza o teste para esse nível de desagregação. 


\section{GRÁFICO 14 - NÚCLEO ESTOCÁSTICO DO PIBr DOS ESTADOS CONDICIONADO À ABERTURA COMERCIAL}

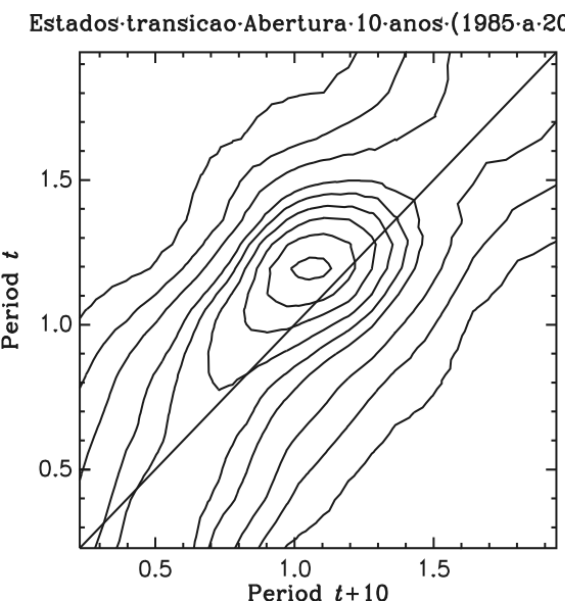

\subsection{Condicionamento pela Desigualdade de Renda}

Na década de 1990 surgiu um grande interesse na literatura de crescimento econômico em aprofundar questões relacionadas aos efeitos da desigualdade. Alguns estudos têm apontado para a possibilidade de uma relação negativa entre índices de desigualdade e taxa de crescimento da renda per capita. As janelas através das quais a desigualdade afetaria o crescimento estariam resumidas em quatro abordagens distintas: modelos de economia política, modelos com imperfeições no mercado de créditos, modelos de estabilidade social e modelos de acumulação de capital.

A idéia principal que fundamenta o primeiro tipo de $\operatorname{argumento}^{16}$ repousa no fato de que sob uma distribuição desigual de renda e riqueza o eleitor mediano desejaria aumentar sua renda no curto prazo a partir de políticas tributárias redistributivas do capital para o trabalho. Desta forma, no processo político, propostas que possuíssem tal aspiração tenderiam a ser sancionadas, o que dificultaria a acumulação de capital no longo prazo. No entanto, tais conclusões poderiam não ser válidas se a arrecadação proveniente de impostos fosse utilizada adequadamente no fornecimento de bens públicos pró-crescimento. Deste modo, neste aspecto, seria difícil prognosticar o efeito líquido da desigualdade sobre o crescimento. (Bertola, 1993; Cooper 1998).

As imperfeições no mercado de crédito podem também ter um efeito perverso sobre o crescimento. Indivíduos considerados aptos a se engajar em projetos produtivos específicos com certa probabilidade de sucesso possuem informações que não são co-

16 Veja, por exemplo, essa discussão em Person e Tabellini (1994) e Alesina e Rodrik (1994). 
nhecidas plenamente por todo o mercado. Para garantir uma estrutura de incentivos adequada, os financiadores acabam demandando colateral dos tomadores de recursos, o que provoca um equilíbrio com racionamento de crédito. Como uma das conseqüências, somente empresários com suficientemente alto níveis de riqueza pessoal estariam habilitados a financiar seus projetos, o que dificultaria a participação de outros empreendedores na geração de riqueza. (Aghion et alii, 1999).

$\mathrm{Na}$ terceira linha de argumentação, a desigualdade pode criar barreiras que afetam o custo da interação social e do capital social. (Collier 1998; Bourguignon 1998). Ademais, ela também pode estar diretamente associada à produção de bens ditos "ruins", tais como violência e crime, que geram prejuízos diretos, uma vez que faria com que o Estado desviasse recursos para atividades preventivas ou de correçóes de desvios sociais e não em atividades produtivas. Os distúrbios sociais podem ter também uma influência negativa sobre os incentivos ao investimento, posto que aumentaria a insegurança induzida sobre os direitos de propriedade.

Por último, a desigualdade poderia afetar positivamente o crescimento econômico por meio do efeito-poupança. Talvez influenciado pela obra de Keynes, alguns economistas acreditam que taxas de poupança individuais aumentariam com o nível de renda e, deste modo, a redistribuição de recursos de ricos para pobres reduziria a taxa de poupança média da economia e desta forma o nível de investimentos. Esse argumento, no entanto, como visto em Barro (2000), pode não ser correto para economias com baixos níveis de renda, porquanto a desigualdade não teria efeito no aumento da taxa de poupança.

Assim, uma vez descritos esses quatro argumentos, não se pode a priori determinar qual o efeito líquido da desigualdade no crescimento econômico. Usando o índice de Gini como medida de desigualdade, tanto para os Estados como os municípios, constata-se, pelo Gráfico 15, a baixa concentração em torno da média dos PIBr condicionados à desigualdade de renda. ${ }^{17}$ Ademais, verifica-se que os núcleos estocásticos (Gráfico 16) são muito semelhantes aos não-condicionados, o que é um indício de que a desigualdade de renda pode não ser considerada como um fator determinante na explicação das disparidades de rendas observadas. Ou seja, os fatores que levariam a desigualdade a reduzir o crescimento poderiam estar sendo compensados por outros elementos pró-crescimento. Investigações adicionais seriam necessárias para estabelecer conclusões mais robustas neste aspecto.

$17 \mathrm{O}$ condicionamento por desigualdade de renda (Gráfico $15 \mathrm{~b}$ ) produziu o mesmo resultado do caso não-condicionado. Isto é um indício de que esta forma de condicionamento não é significante para o crescimento. Assim sendo, condicionar por desigualdade produz o mesmo resultado do que qualquer outra forma aleatória de agrupamento dos municípios, qual seja, um resultado igual à distribuição não-condicionada. 
GRÁFICO 15 - DENSIDADE DO PIBr CONDICIONADA À DESIGUALDADE

$15 A-\operatorname{ESTADOS}(2000)$

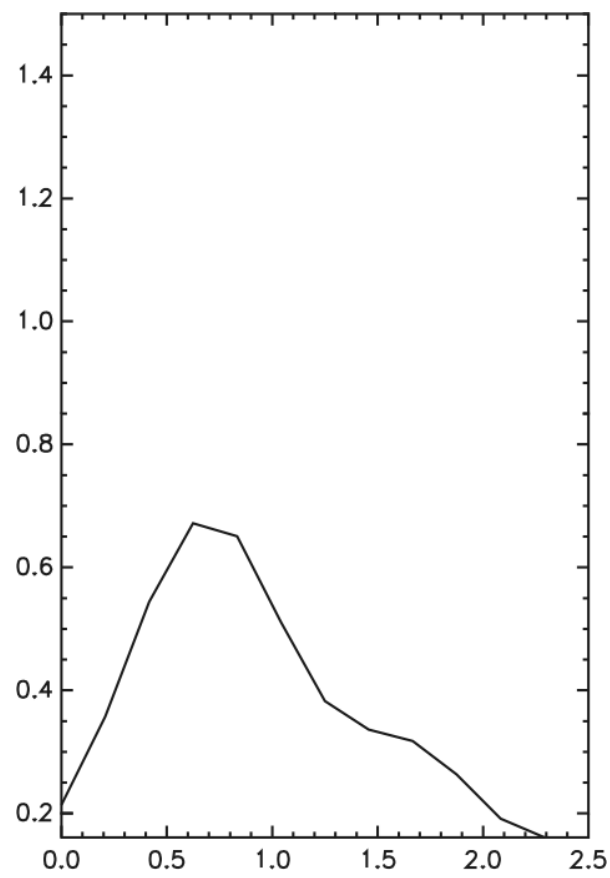

15B - MUNICÍPIOS (2000)

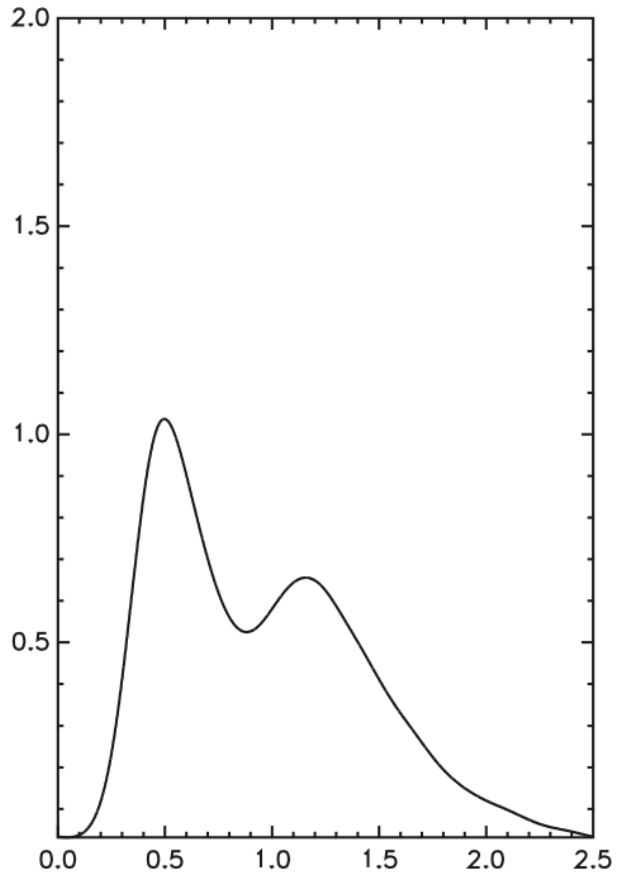

GRÁFICO 16 - NÚCLEO ESTOCÁSTICO DO PIBr CONDICIONADO À DESIGUALDADE DE RENDA

$16 A-E S T A D O S$

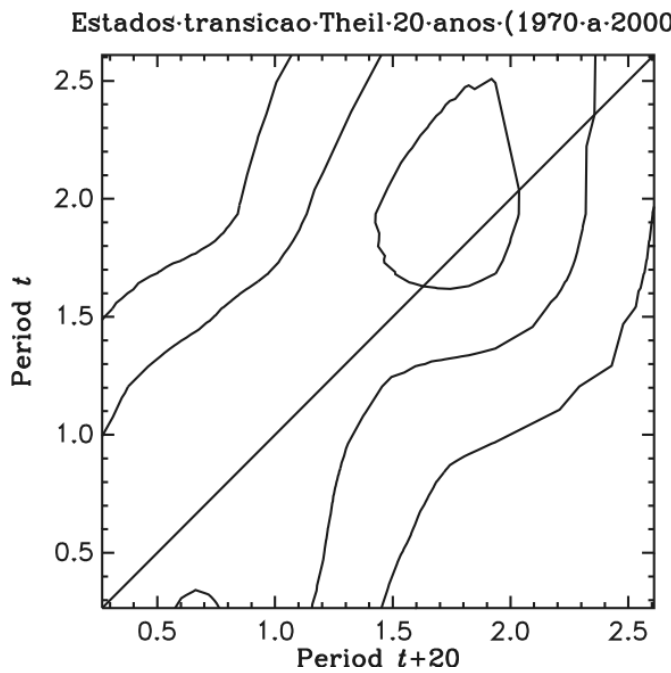

16B-MUNICÍPIOS

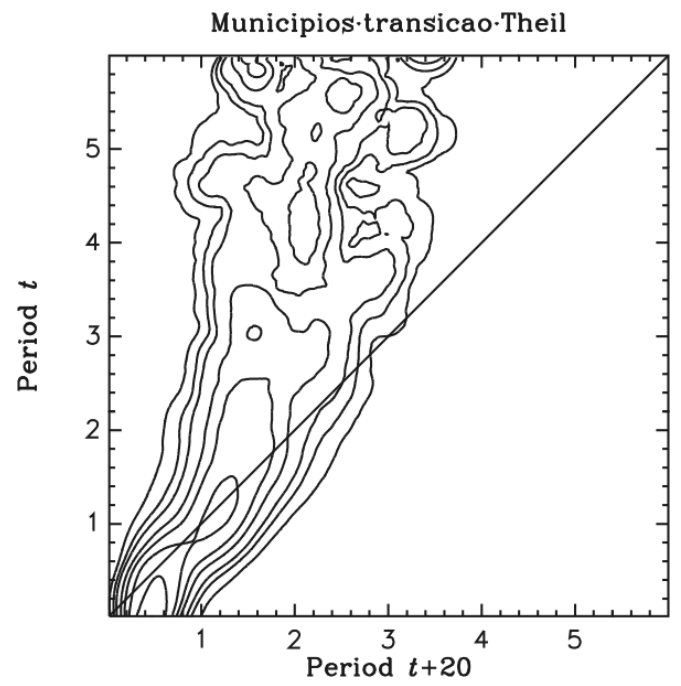




\section{CONCLUSÕES}

Grande parte da literatura que investiga a possibilidade de existência de $\beta$-convergência no Brasil tem detectado a ocorrência de fraca tendência ou até mesmo a não existência de convergência entre as regiões brasileiras. Para regressões cross-section estes resultados podem estar sendo influenciados pela Falácia de Galton. Para evitarmos tal problema seguimos a metodologia proposta por Quah (1997) e encontramos evidência, como também já constatada em Mossi et alii (2003) e Andrade et alii (2004), acerca da existência de clubes de convergência no Brasil, em que o Norte e Nordeste formariam um clube, e o Sul, Sudeste e Centro-Oeste, outro. Além disso, este trabalho dá um passo adicional nessa discussão ao investigar a influência de determinadas variáveis como possíveis condicionantes de tal processo. Neste sentido, investigamos se a educação, integração comercial, proximidade geográfica e desigualdade de renda têm alguma importância na formação de clubes de convergência.

Os principais resultados apontam que tanto no nível de municípios quanto de Estados, o nível de escolaridade e a localização geográfica seriam fatores importantes na formação desses clubes. O fator geográfico mostrou-se mais significante através do canal de proximidade, um indicador possível de que a localização relativa seria mais importante do que a localização absoluta. Em outras palavras, as unidades territoriais mais pobres encontrariam dificuldade de se livrar desta condição de pobreza relativa por estarem cercadas de outras economias pobres. Por outro lado, a maior integração ao comércio internacional e a desigualdade renda sinalizam não terem influência sobre a desigualdade regional no Brasil.

Evidentemente, pesquisas adicionais que pudessem testar outras formas de medição de integração comercial e sua investigação no nível de municípios ajudariam a aprofundar e esclarecer, com mais segurança, esse efeito. No caso do índice de Gini, a sua pouca importância na formação de clubes de convergência pode ser explicada pela heterogeneidade no tamanho dos PIBs das unidades da amostra utilizada, o que poderia provocar efeitos em direções opostas, como considerado em Barro (2000). Também seria oportuno aprofundar essa discussão testando outros condicionantes advindos de variáveis institucionais, de saúde e infra-estrutura. 


\section{BIBLIOGRAFIA}

Ades, A. F; Glaeser, E. L. Trade and circuses: explaining urban giants. Quarterly Journal of Economics, v. 110, n. 1, p. 195-227, 1997.

Aghion, P.; Caroli, E.; García-Peñalosa, C. Inequality and economic growth: the perspective of the new growth theories. Journal of Economic Literature, v. 37, n. 4, p. 1615-1660, December 1999.

Alesina, A.; Rodrik D. Distribution polities and economic growth. Quarterly Journal of Economics, 109, p. 465-490, 1994.

Andrade, E.; Laurini, M.; Madalozzo, R.; Pereira, P. L.Vals. Convergence clubs among Brazilian municipalities. Economic Letters, 83, p. 179-184, 2004.

Barro, R. Inequality and growth in a panel of countries. Journal of Economic Growth, v. 5 , n. 1, p. 87-120, March 2000.

. Economic growth in a cross section of countries. QJE, 106, p. 407-43, May 1991.

Barro, R.; Sala-i-Martin, X. Convergence. Journal of Political Economy, v. 100, n. 2, 1992.

Baumol, W. J. Productivity growth, convergence and welfare. American Economic Review, 76, p. 1072-1085, December 1986.

Baumol, W. J.; Blackman, S. A. B.; Wolff, E. N. Productivity and American leadership: the long view. Cambridge, MA.: MIT Press, 1989.

Bertola, G. Factor shares and savings in endogenous growth. American Economic Review. 83, p. 1184-1198, 1993.

Bliss, C. Galton's fallacy and economic convergence. Oxford Economic Paper, 51, p. 4-14, 1999.

Bourguignon, F; Morrisson, C. Inequality and development-the role of dualism. Journal of Development Economics, v. 57, p. 233-257, 1998.

Cannon, E. S.; Duck, Nigel W. Galton's fallacy and economic convergence. Oxford Economic Paper, 52, p. 415-419, 2000.

Collier, P. Social capital and poverty social capital initiative. Working Paper 4, Washington, D.C.: World Bank, Social Development, 1998.

Cooper, S. J. A positive theory of income redistribution. Journal of Economic Growth, 3, p. 171-95, 1988.

Dollar, D. Outward-oriented developing economies really do grow more rapidly: evidence from 95 LDCs, 1976-85. Economic Development and Cultural Change, p. $523-544,1992$.

Durlauf, S.; Quah, D. The new empirics of economic growth, CEPR Discussion Paper $\mathrm{n}^{\mathrm{o}}$ 384, Handbook of Macroeconomics, Elsevier Science, 1998. 
Edwards, S. Openness, productivity and growth: what do we really know? Economic Journal, p. 383-398, March 1998.

Ellery Jr; Ferreira, P. Convergência entre a renda per capita dos estados brasileiros. Revista de Econometria, v. 16, n. 1, p. 83-103, 1996.

Ferreira, A. Concentração regional e dispersão das rendas per capita estaduais: um comentário. Estudos Econômicos, v. 29, n. 1, p. 47-63, jan./mar. 1999.

. Convergence in Brazil: recent trends and long-run prospects. Applied Economics, 32, p. 479-489, 2000.

. Evolução recente da renda per capita estaduais no Brasil: o que a nova evidência mostra. Revista Econômica do Nordeste, v. 27, n. 3, p. 363-374, jul/set. 1996.

Ferreira, A.; Diniz, C. Convergência entre as rendas per capita estaduais no Brasil. Revista de Economia Politica, v. 15, n. 4 (60), 1995.

Frankel, J.; Romer, D. Does trade cause growth? American Economic Review, v. 89, n. 3, p. 379-399, June 1999.

Friedman, M. Do old fallacies ever die? Journal of Economic Literature, v. 30, p. 2129 2132, 1992.

Fujita, M.; Krugman, P.; Venables, A. The spatial economy. MIT Press, 1999.

Grossman, G; Helpman, E. Innovation and growth. MIT Press, 1991.

Hers, J. Human capital and economic growth: a survey of the literature. CPB Report, 1988. Mimeografado.

Jones, C. On the evolution of the world income distribution. Journal of Economic Perspectives, v. 11, n. 3, p. 19-36, Summer 1997.

Laurini, M.; Andrade, E.; Pereira, P. Clubes de convergência de renda para os municípios brasileiros: uma análise não-paramétrica. XXV Encontro Brasileiro de Econometria - SBE, 2003.

Lucas, R. On the mechanics of economic development. Journal of Monetary Economics, 22, p. 3-42, 1988.

Mossi, M. B.; Aroca, P.; Fernández, I. J.; Azzoni, C. R. Growth dynamics and space in Brazil. International Regional Science Review, v. 26, n. 3, p. 393-418, July 2003.

Person, T.; Tabellini, G. Is inequality harmful for growth? Theory and evidence. American Economic Review 84, p. 600-621, 1994.

Quah, D. Empirical cross-section dynamics in economic growth. European Economic Review, v. 37, n. 2/3, p. 426-434, April 1993.

. Empirics for economic growth and convergence. European Economic Review 40, p. 1353-75, 1996. 
. Empirics for growth and distribution: stratification, polarization and convergence clubs. Journal of Economic Growth, v. 2, n. 1, p. 27-59, March 1997.

Rodriguez, F; Rodrik, D. Trade policy and economic growth: a skeptic's guide to the cross-national evidence. NBER Macroeconomics Annual 2000.

Silverman, B. Density estimation for statistics and data analysis. Chapman \& Hall/CRC, 1986.

Zini Jr., A. A. Regional income convergence in Brazil and its socio-economic determinants. Economia Aplicada, v. 2, n. 2, p. 383- 411, abr./jun. 1998.

ANEXO-DADOS

\section{PIB per capita}

a) PIB dos Estados, mil R \$ de 2000, obtido no IPEADATA.

Fontes:1970 a 1980: Produto Interno Bruto a custos de fatores (IBGE); 1985 a 2000: Produto Interno Bruto a preços de mercado (IBGE).

b) PIB Municipal - R $\$$ de 2000, obtido no IPEADATA.

Fontes: 1970 e 1980: Produto Interno Bruto a custo de fatores (IPEA); 1991 e 2000: subíndice do IDH relativo à dimensão renda (IPEA).

c) População brasileira, série anual, obtida pela divisão do PIB Brasil pelo PIB per capita Brasil, ambas a preços de 2000, do IPEADATA.

d) População dos Estados dos anos 1980 a 2000, série anual, obtida de estimativas do IBGE.

e) População dos Estados do ano 1970 obtida no IPEADATA.

Fonte: Censos Demográficos (IBGE).

f) População dos Estados dos anos compreendidos entre os Censos 1970 e 1980, calculada a partir da mesma metodologia utilizada pelo IBGE no cálculo das estimativas de 1980 a 2000. 
g) PIB per capita dos Estados obtido a partir da divisão do PIB dos Estados pela população.

\section{Capital Humano}

a) Número médio de anos de estudo das pessoas de 25 ou + anos de idade - Decenal: 1970 - Ano/Série (IPEADATA).

\section{Institucional}

a) Índice de Gini - Decenal: 1970 - Índice (IPEADATA).

4. Abertura Comercial (dados de 1991-MDIC/SECEX)

a) (Exportações + Importações ) / PIB. 